\title{
Population Pharmacokinetic/Pharmacodynamic Modeling of Sunitinib by Dosing Schedule in Patients with Advanced Renal Cell Carcinoma or Gastrointestinal Stromal Tumor
}

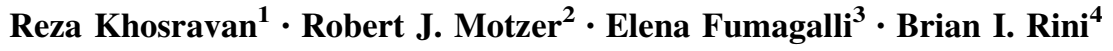

Published online: 6 May 2016

(c) The Author(s) 2016. This article is published with open access at Springerlink.com

\begin{abstract}
Background Sunitinib is a multi-targeted tyrosine kinase inhibitor used in the treatment of advanced renal cell carcinoma (RCC) and imatinib-resistant/intolerant gastrointestinal stromal tumors (GIST).

Methods A meta-analysis of 10 prospective clinical studies in advanced RCC and GIST was performed to support the development of pharmacokinetic (PK) and PK/pharmacodynamic (PD) models that account for the effects of important covariates. These models were used to make predictions with respect to the PK, safety, and efficacy of sunitinib when administered on the traditional 4-weeks-on/ 2-weeks-off schedule (Schedule 4/2) versus an alternative schedule of 2 weeks on/1 week off (Schedule 2/1).

Results The covariates found to have a significant effect on one or more of the PK or PD parameter studies included, age, sex, body weight, race, baseline Eastern Cooperative Oncology Group performance status, tumor type, and dosing schedule. The models predicted that, in both RCC and GIST patients, Schedule 2/1 would have comparable efficacy to Schedule 4/2, despite some differences in PK
\end{abstract}

Electronic supplementary material The online version of this article (doi:10.1007/s40262-016-0404-5) contains supplementary material, which is available to authorized users.

Reza Khosravan

Reza.Khosravan@pfizer.com

1 Pfizer Oncology, 10646 Science Center Drive, CB10, La Jolla, CA 92121, USA

2 Memorial Sloan Kettering Cancer Center, New York, NY, USA

3 Fondazione IRCCS Istituto Nazionale dei Tumori, Milan, Italy

4 Cleveland Clinic, Cleveland, OH, USA profiles. The models also predicted that, in both indications, sunitinib-related thrombocytopenia would be less severe when sunitinib was administered on Schedule 2/1 dosing compared with Schedule 4/2.

Conclusion These findings support the use of sunitinib on Schedule $2 / 1$ as a potential alternative to Schedule $4 / 2$ because it allows for the management of toxicity without loss of efficacy.

\section{Key Points}

This analysis compared the efficacy and safety of sunitinib administered on Schedule 2/1 dosing versus Schedule $4 / 2$ (i.e. weeks on/weeks off) using mechanism-based and semi-mechanistic pharmacokinetic/pharmacodynamic models.

The models predicted that efficacy with sunitinib administered on Schedule 2/1 would be comparable to Schedule $4 / 2$, but thrombocytopenia would be less severe on Schedule 2/1.

Schedule 2/1 may be a preferred regimen for sunitinib in patients with advanced RCC or gastrointestinal stromal tumors as it is predicted to be as efficacious with better tolerability compared with Schedule 4/2.

\section{Introduction}

Sunitinib is an orally administered, multi-targeted tyrosine kinase inhibitor with potent antiangiogenic and antitumor activity [1]. The advent of sunitinib and other antiangiogenic 
therapies has revolutionized the therapeutic landscape for patients with advanced renal cell carcinoma (RCC) or imatinib-resistant/intolerant gastrointestinal stromal tumors (GIST), considerably improving outcomes compared with previous management paradigms [2-4]. For any therapeutic agent, a key challenge is to achieve efficacy while minimizing treatment-related adverse events (AEs), so that both therapy compliance and on-treatment time are maximized [5]. It is recommended that sunitinib $(50 \mathrm{mg}$ once daily) be administered for 4 consecutive weeks followed by 2-weeks-off treatment ('Schedule 4/2') in RCC and GIST patients, as was employed in the pivotal phase III trials in these indications $[2,6]$. However, due to drug toxicity, $28-38$ and $11-32 \%$ of sunitinib-treated patients in these trials experienced dose interruptions and reductions, respectively $[2,6]$, instigating efforts to optimize the dosing schedule to improve tolerance. In an open-label, phase II trial of cytokine-refractory metastatic RCC patients, continuous daily dosing (CDD) with $37.5 \mathrm{mg}$ displayed a manageable safety profile [7]. However, no difference in $\mathrm{AE}$ incidence between this regimen and Schedule 4/2 was observed in a randomized, phase II trial that directly compared these regimens as first-line therapy in patients with advanced RCC. Furthermore, time to tumor progression (TTP) was numerically longer on Schedule $4 / 2$ than CDD [8]. In patients with imatinib-resistant/intolerant GIST, an open-label, phase II trial showed CDD with $37.5 \mathrm{mg}$ to be active, with an acceptable safety profile [9]. These results were broadly similar to those of the phase III trial of sunitinib in GIST [2, 9].

A previous pharmacokinetic/pharmacodynamic (PK/ PD) meta-analysis of data from studies in patients with solid tumors, including RCC and GIST, predicted that increased sunitinib exposure was associated with improved efficacy but increased AE risk [10]. With the aim of preserving sunitinib efficacy while minimizing treatment-related toxicity, the utility of a 2-weeks-on/1-week-off schedule ('Schedule 2/1') in RCC has been investigated in clinical practice. Retrospective reports suggest that with Schedule $2 / 1$ dosing, the efficacy of sunitinib was preserved and the toxicity profile was more manageable than Schedule 4/2 [11-14]. Data comparing the efficacy and safety of Schedule 4/2 with Schedule 2/1 in GIST patients are currently lacking [15].

It has been previously shown that the efficacy and toxicity of sunitinib could be predicted by PK/PD modeling $[10,16]$. Our objective was to develop PK and PK/PD models that took into account the effects of important covariates by pooling data from 10 prospective clinical studies in adult patients with RCC or GIST. The models were used to make predictions with respect to the PK, safety, and efficacy of sunitinib in these patients on Schedule 2/1 compared with Schedule 4/2.

\section{Methods}

\subsection{Study Designs}

This retrospective PK/PD meta-analysis pooled data from 10 phase I-III clinical studies. Six studies were conducted in patients with advanced RCC $(N=578$ total evaluable patients, of whom 395 patients were included in the PK analysis) [7, 8, 17-20]. Sunitinib was administered orally according to one of two schedules: Schedule $4 / 2$ at $50 \mathrm{mg}$ or CDD $37.5 \mathrm{mg}$. Four studies were conducted in patients with advanced GIST exhibiting resistance or intolerance to imatinib $(N=365$ total evaluable patients, of whom 252 patients were included in the PK analysis) [9, 21-23]. Sunitinib was administered orally according to one of the following schedules: Schedule 4/2, doses between 25 and $75 \mathrm{mg}$; Schedule 2/2, doses between 25 and $75 \mathrm{mg}$; Schedule 2/1 at $50 \mathrm{mg}$; or CDD $37.5 \mathrm{mg}$. All studies were approved by Institutional Review Boards or independent Ethics Committees, and all patients provided written informed consent.

\subsection{Study Assessments}

Blood samples for PK assessments were taken at prespecified visits per each study protocol (trough PK: all studies; full profile PK: two studies). Plasma samples were analyzed for quantification of the concentrations of sunitinib and its active metabolite SU12662 using a validated liquid chromatography-tandem mass spectrometry assay (BASi, West Lafayette, IN, USA), as previously described [31]. Tumor measurements were recorded regularly (once every cycle or every other cycle following each study protocol requirements) and responses defined using Response Evaluation Criteria in Solid Tumors (RECIST), version 1.0 [24]. Safety and tolerability were assessed regularly and AEs were graded according to National Cancer Institute Common Terminology Criteria for Adverse Events, version 3.0.

\subsection{Pharmacokinetic (PK) Models}

PK data were pooled and randomly split, at study and subject level, into the working dataset used to develop the PK models $(70 \%)$ and the external validation dataset (30\%). Plasma concentration-time data for sunitinib and SU12662 were each separately analyzed using nonlinear mixed-effects modeling (NONMEM, version 7.1.2) [25] to estimate population PK parameters (mean and intersubject variability) and identify potential covariates to explain intersubject variability in the parameters. Analyses were performed using the first-order conditional estimation method with interaction (FOCEI) approximation method in 
NONMEM. Methods used to generate and validate the PK models are described in the Methods section in the electronic supplementary material (ESM).

\subsection{PK/Pharmacodynamic (PD) Model}

Sequential PK/PD modeling was performed using the FOCEI approximation method. The efficacy endpoint modeled was target tumor sum of the largest diameter (SLD). Modeled safety endpoints were related to the most common sunitinib AEs and included absolute neutrophil count (ANC), platelet count (PC), lymphocyte count (LC), diastolic blood pressure (DBP), alanine aminotransferase (ALT), aspartate aminotransferase (AST), and left ventricular ejection fraction (LVEF) [2, 6]. The type of PK/PD modeling performed to distinguish between the effects on safety of different dosing schedules (while total dose over a 42-day cycle remained unchanged) required the presence of continuous quantitative safety measures/endpoints. Therefore, the PK/PD modeling approach could not be applied to categorical safety endpoints (e.g. fatigue, handfoot syndrome, nausea, vomiting, diarrhea, or others). Only PK model-predicted sunitinib concentrations were used to build the PK/PD models (see the Methods section in the ESM regarding the development of the PK/PD models).

\subsection{Patient Population Simulation}

Using the final population $\mathrm{PK}$ and $\mathrm{PK} / \mathrm{PD}$ models, trial simulations were performed to provide predictions with respect to the PK of sunitinib and SU12662, and the safety and efficacy of sunitinib $50 \mathrm{mg}$ on Schedule $2 / 1(n=100)$ compared with Schedule 4/2 $(n=100)$ in patients with advanced RCC or GIST. For the purpose of this simulation exercise, a full cycle was defined as a 42-day period. For Schedule 4/2, a full cycle comprised 28 days of daily dosing followed by 14 days off treatment. For Schedule $2 / 1$, a full cycle comprised two periods of 14 days of daily dosing followed by 7 days off treatment. A total of 20 trial simulations were run in which RCC or GIST patients were assigned demographics consistent with those from the pooled dataset for the RCC or GIST patient population from the sunitinib trials dataset included in the modeling portion. One set of trial simulations was run to predict the values of target tumor SLD during cycle 6 for each dosing schedule, and the values of the safety endpoints during cycle 3. Another set was run to predict the incidence rates of different grades of AEs during the first three cycles and the progression-free survival (PFS)/TTP and objective response rate (ORR) values based on the predicted SLD for each dosing schedule (see the Methods section in the ESM).

\section{Results}

\subsection{Baseline Patient Characteristics and Covariates}

Data from 647 patients with advanced RCC or GIST contributed to the analysis. Baseline patient characteristics of the working dataset, summarized in Table 1, were generally representative of the original trial populations. The patient characteristics of the validation dataset resembled those of the working dataset. In all, 395 $(61.1 \%)$ and $252(38.9 \%)$ RCC and GIST patients, respectively, were included in the analysis. The PK analysis included patients from all dosing schedules (\% patients), including Schedule 4/2 (63.4\%), a 2-weeks-on/ 2-weeks-off schedule (Schedule 2/2;3.1\%), Schedule 2/1 $(0.8 \%)$, and $\mathrm{CDD}(32.8 \%)$. All patients receiving Schedules $2 / 2$ and $2 / 1$ had GIST. Of the PK patient population, only a subset of patients who had the specific efficacy or safety endpoints from all dosing regimens were included in the PK/PD analysis.

In the analyses described below, the following covariates were found to have a significant effect on one or more of the PK or PD parameters studied: age (AGE), sex (SEX), body weight (BWT), race (RAC), baseline Eastern Cooperative Oncology Group performance status (ECOG PS $[\mathrm{BEC}]$ ), tumor type (TUMR), and dosing schedule (SCH).

\subsection{PK Models}

A two-compartment model with first-order rates of absorption $\left(K_{\mathrm{a}}\right)$ and elimination $\left(K_{\mathrm{e}}\right)$ was developed and validated for sunitinib and its primary metabolite SU12662. Absorption lag time $\left(t_{\text {lag }}\right)$ was included in the sunitinib PK model, but not for SU12662. PK parameter estimates from the final and bootstrap models for sunitinib and its metabolite are summarized in Table 2.

The PK parameters with significant covariate effects in the final model for sunitinib, plus the significant covariates themselves, are shown in Eqs. 1 and 2:

$$
\begin{aligned}
\mathrm{CL} / F= & 34.1 \times(1-0.00702 \times(\mathrm{AGE}-58)) \\
& \times(1-0.152 \times \mathrm{RAC}) \times(1-0.193 \times \mathrm{SEX}) \\
& \times(1+0.293 \times \mathrm{TUMR}) ; \\
V_{\mathrm{c}} / F= & 2700 \times(\mathrm{BWT} / 77.4)^{0.281} \times(1-0.213 \times \mathrm{SEX}) \\
& \times(1+0.42 \times \mathrm{TUMR}) .
\end{aligned}
$$

Thus, sunitinib apparent clearance (CL/F) decreased with age $(-0.702 \%$ per year), Asian ethnicity $(-15.2 \%)$, and in females $(-19.3 \%)$, and increased in patients with GIST $(+29.3 \%)$. Sunitinib central compartment volume $\left(V_{\mathrm{c}} / F\right)$ increased in patients with GIST $(+42 \%)$ and as BWT increased (e.g. $+20.4 \%$ for 150 vs. $77.4 \mathrm{~kg}$ ), and decreased in females $(-21.3 \%)$. 
Table 1 Baseline patient characteristics $(N=647)^{\mathrm{a}}$

\begin{tabular}{|c|c|c|c|c|}
\hline & $n$ & Mean \pm SD & Median & Range \\
\hline \multicolumn{5}{|l|}{ Continuous variables } \\
\hline Age, years & 647 & $57.6 \pm 11.2$ & 58 & $23-84$ \\
\hline Body weight, $\mathrm{kg}$ & 641 & $77.4 \pm 19.3$ & 77.2 & $39.1-154$ \\
\hline Height, $\mathrm{cm}$ & 631 & $169 \pm 10.4$ & 170 & $137-201$ \\
\hline Body surface, $\mathrm{m}^{2}$ & 629 & $1.87 \pm 0.255$ & 1.87 & $1.24-2.6$ \\
\hline AST, U/L & 637 & $24.8 \pm 13.1$ & 22 & $3-114$ \\
\hline ALT, U/L & 637 & $25.6 \pm 17.5$ & 22 & $4-168$ \\
\hline $\mathrm{CrCl}, \mathrm{mL} / \mathrm{min}$ & 631 & $81.8 \pm 29.9$ & 78.1 & $24.2-241$ \\
\hline Diastolic BP, mmHg & 644 & $74.8 \pm 10.6$ & 75 & $20-100$ \\
\hline ANC, $10^{9} / \mathrm{L}$ & 591 & $5.06 \pm 2.5$ & 4.51 & $1.15-21.8$ \\
\hline Platelet count, $10^{9} / \mathrm{L}$ & 635 & $316 \pm 137$ & 280 & $102-1070$ \\
\hline Lymphocyte count, $10^{9} / \mathrm{L}$ & 591 & $1.62 \pm 0.859$ & 1.47 & $0.3-12.7$ \\
\hline Hemoglobin, g/dL & 628 & $50.6 \pm 53$ & 14.1 & $5.1-163$ \\
\hline LVEF, \% & 424 & $64.4 \pm 7.47$ & 65 & $45-85$ \\
\hline \multicolumn{5}{|l|}{ Categorical variables $[n(\%)]$} \\
\hline \multicolumn{5}{|l|}{ Race } \\
\hline White & \multicolumn{4}{|c|}{$472(73.0)$} \\
\hline Black & \multicolumn{4}{|c|}{$21(3.2)$} \\
\hline Asian & \multicolumn{4}{|c|}{$103(15.9)$} \\
\hline Hispanic & \multicolumn{4}{|c|}{$29(4.5)$} \\
\hline Unknown & \multicolumn{4}{|c|}{$22(3.4)$} \\
\hline \multicolumn{5}{|l|}{ Sex } \\
\hline Male & \multicolumn{4}{|c|}{$426(65.8)$} \\
\hline Female & \multicolumn{4}{|c|}{$221(34.2)$} \\
\hline \multicolumn{5}{|l|}{ ECOG PS } \\
\hline 0 & \multicolumn{4}{|c|}{$297(45.9)$} \\
\hline 1 & \multicolumn{4}{|c|}{$216(33.4)$} \\
\hline 2 & \multicolumn{4}{|c|}{$132(20.4)$} \\
\hline Unknown & \multicolumn{4}{|c|}{$2(0.3)$} \\
\hline \multicolumn{5}{|l|}{ Tumor type } \\
\hline $\mathrm{RCC}$ & \multicolumn{4}{|c|}{$395(61.1)$} \\
\hline GIST & \multicolumn{4}{|c|}{$252(38.9)$} \\
\hline \multicolumn{5}{|l|}{ Schedule ${ }^{\mathrm{b}}$} \\
\hline $4 / 2$ & \multicolumn{4}{|c|}{$410(63.4)$} \\
\hline $2 / 2$ & \multicolumn{4}{|c|}{$20(3.1)$} \\
\hline $2 / 1$ & \multicolumn{4}{|c|}{$5(0.8)$} \\
\hline CDD & \multicolumn{4}{|c|}{$212(32.8)$} \\
\hline
\end{tabular}

$A L T$ alanine aminotransferase, $A N C$ absolute neutrophil count, $A S T$ aspartate aminotransferase, $B P$ blood pressure, $C D D$ continuous daily dosing, $\mathrm{CrCl}$ creatinine clearance, ECOG PS Eastern Cooperative Oncology Group performance status, GIST gastrointestinal stromal tumor, $L V E F$ left ventricular ejection fraction, $P K$ pharmacokinetic, $R C C$ renal cell carcinoma, $S D$ standard deviation

${ }^{a}$ Based on the working PK dataset for patients with at least one measurable PK sample

${ }^{b}$ Weeks on/weeks off treatment or CCD
PK parameters with significant covariate effects in the final model for SU12662 were as shown in Eqs. 3 and 4:

$$
\begin{aligned}
\mathrm{CL} / F= & 17.5 \times(1-0.00743 \times(\mathrm{AGE}-58)) \\
& \times(1-0.205 \times \mathrm{RACE}) \times(1-0.354 \times \mathrm{SEX}) \\
& \times(1+0.324 \times \mathrm{TUMR}) ;
\end{aligned}
$$

$$
\begin{aligned}
V_{\mathrm{c}} / F= & 2120 \times(1+0.00892 \times(\mathrm{BWT}-77.3)) \\
& \times(1-0.272 \times \mathrm{SEX}) \times(1+0.635 \times \mathrm{TUMR}) .
\end{aligned}
$$

Thus, the same covariates influenced SU12662 $\mathrm{CL} / F$ and $V_{\mathrm{c}} / F$, as in the model for sunitinib. SU12662 $\mathrm{CL} / F$ decreased with age $(-0.743 \%$ per year $)$, Asian 
Table 2 Summary of PK parameters for sunitinib and its active metabolite SU12662 in the final population PK models

\begin{tabular}{|c|c|c|c|c|}
\hline \multirow[t]{2}{*}{ Parameter } & \multicolumn{2}{|l|}{ Sunitinib } & \multicolumn{2}{|l|}{ SU12662 } \\
\hline & Final model results & Bootstrap model results & Final model results & Bootstrap model results \\
\hline \multicolumn{5}{|c|}{ Population mean estimates $(95 \% \mathrm{CI})^{\mathrm{a}}$} \\
\hline $\mathrm{CL} / F, \mathrm{~L} / \mathrm{h}$ & $34.1(32.7-35.5)$ & $34.9(33.0-35.8)$ & $17.5(16.5-18.5)$ & $17.3(16.5-18.3)$ \\
\hline$V_{\mathrm{c}} / F, \mathrm{~L}$ & $2700(2543-2857)$ & $2720(2320-2800)$ & $2120(1925-2315)$ & $2130(1860-2420)$ \\
\hline$K_{\mathrm{a}}, \mathrm{h}^{-1}$ & $0.126(0.106-0.146)$ & $0.116(0.134-0.201)$ & $0.102(0.0714-0.133)$ & $0.108(0.0733-0.154)$ \\
\hline$t_{\text {lag }}, \mathrm{h}$ & $0.527(0.508-0.546)$ & $0.529(0.507-0.954)$ & NA & NA \\
\hline$V_{\mathrm{p}} / F, \mathrm{~L}$ & $774(713-835)$ & $806(523-1210)$ & $751(708-794)$ & $762(535-1170)$ \\
\hline$Q / F, \mathrm{~L} / \mathrm{h}$ & $0.688(0.651-0.725)$ & $0.676(0.564-0.833)$ & $0.979(0.904-1.05)$ & $1.01(0.736-1.37)$ \\
\hline $\begin{array}{l}\text { AGE on } \\
\text { CL/F }\end{array}$ & $\begin{array}{l}-0.00702(-0.00916 \text { to } \\
-0.00488)\end{array}$ & $\begin{array}{l}-0.00772(-0.00935 \text { to } \\
-0.00553)\end{array}$ & $\begin{array}{l}-0.00743(-0.0103 \text { to } \\
-0.00457)\end{array}$ & $\begin{array}{l}-0.00777(-0.0107 \text { to } \\
-0.00465)\end{array}$ \\
\hline $\begin{array}{l}\mathrm{RAC} \text { on } \\
\mathrm{CL} / F\end{array}$ & $-0.152(-0.209$ to -0.0954$)$ & $-0.158(-0.216$ to -0.101$)$ & $-0.205(-0.278$ to -0.132$)$ & $-0.200(-0.273$ to -0.118$)$ \\
\hline SEX on CL/F & $-0.193(-0.232$ to -0.154$)$ & $-0.202(-0.252$ to -0.151$)$ & $-0.354(-0.402$ to -0.306$)$ & $-0.348(-0.397$ to -0.295$)$ \\
\hline $\begin{array}{l}\text { TUMR on } \\
\text { CL/F }\end{array}$ & $0.293(0.230-0.356)$ & $0.275(0.200-0.360)$ & $0.324(0.223-0.425)$ & $0.326(0.230-0.429)$ \\
\hline BWT on $V_{\mathrm{c}} / F$ & $0.281(0.128-0.434)$ & $0.281(0.159-0.529)$ & $0.00892(0.00614-0.0117)$ & $0.00752(0.00351-0.0117)$ \\
\hline SEX on $V_{\mathrm{c}} / F$ & $-0.213(-0.275$ to -0.151$)$ & $-0.216(-0.289$ to -0.114$)$ & $-0.272(-0.376$ to -0.168$)$ & $-0.322(-0.431$ to -0.199$)$ \\
\hline $\begin{array}{l}\text { TUMR on } \\
V_{\mathrm{c}} / F\end{array}$ & $0.420(0.316-0.524)$ & $0.427(0.311-0.637)$ & $0.635(0.417-0.853)$ & $0.652(0.435-0.929)$ \\
\hline \multicolumn{5}{|c|}{ Residual variability $\% \mathrm{CV}(95 \% \mathrm{CI})^{\mathrm{a}}$} \\
\hline & $41.7(41.4-42.0)$ & $41.9(39.0-44.0)$ & $36.9(36.5-37.3)$ & $36.9(34.8-38.7)$ \\
\hline \multicolumn{5}{|c|}{ Interpatient variability $\% \mathrm{CV}(95 \% \mathrm{CI})^{\mathrm{a}}$} \\
\hline $\mathrm{CL} / F$ & $24.6(22.8-26.3)$ & $24.1(21.1-27.0)$ & $36.3(33.9-38.6)$ & $36.1(32.8-39.7)$ \\
\hline$V_{\mathrm{c}} / F$ & $23.0(20.4-25.4)$ & $21.9(15.8-29.4)$ & $47.3(43.4-50.9)$ & $49.5(40.0-60.0)$ \\
\hline$K_{\mathrm{a}}$ & $166(146-183)$ & $172(152-202)$ & $126(85.6-156)$ & $130(100-155)$ \\
\hline
\end{tabular}

$B W T$ baseline weight, $C I$ confidence interval, $C L / F$ apparent clearance, $C V$ coefficient of variation, $K_{a}$ absorption rate constant, $N A$ not applicable, $P K=$ pharmacokinetic, $Q / F$ intercompartmental clearance, $R A C$ race, $S E$ standard error, $t_{\text {lag }}$ lag time, $S E X$ sex, $T U M R$ tumor, $V_{c} / F$ central compartment apparent volume of distribution, $V_{p} / F$ peripheral compartment apparent volume of distribution

a $95 \%$ CI was estimated as (mean $-1.96 \times \mathrm{SE}-$ mean $+1.96 \times \mathrm{SE})$

ethnicity $(-20.5 \%)$, and in females $(-35.4 \%)$, and increased in patients with GIST $(+32.4 \%)$. SU012662 $V_{\mathrm{c}} / F$ increased in patients with GIST $(+63.5 \%)$ and as BWT increased $(+0.892 \%$ per $\mathrm{kg})$, and decreased in females $(-27.2 \%)$.

To test the goodness-of-fit of the final PK models for sunitinib and its metabolite, plots were generated, including individual predicted versus observed concentrations (Fig. 1), population predicted versus observed concentrations (Fig. 2), and weighted residuals versus time or predictions (Figs. S1 and S2 of the ESM, respectively). The simulated concentrations agreed well with the observed concentrations using visual predictive check (VPC) techniques for both the working and validation datasets (Figs. 3, 4, respectively). In addition, mean and $95 \%$ confidence interval (CI) values generated by the model were similar to the those generated by bootstrapping (Table 2).

\subsection{Sequential PK/PD Models}

Sequential PK/PD models for efficacy and safety endpoints were built using final PK model-predicted sunitinib concentrations. SU12662 data were not included in this process as tests showed inclusion of predicted metabolite concentrations did not improve the model objective function value and was associated with longer run times. Results for the PK/PD models are summarized in Table 3.

\subsubsection{Efficacy Endpoint: Target Tumors' Sum of Longest Diameters}

A sequential indirect response (IDR) PK/PD model (Fig. 5a), with a tolerance function $\left(K_{\text {tol }}\right)$ on the output elimination rate $\left(K_{\text {out }}\right)$ and a maximum drug effect $\left(E_{\max }\right)$ effect function on the input rate constant $\left(K_{\text {in }}\right)$, was used as 


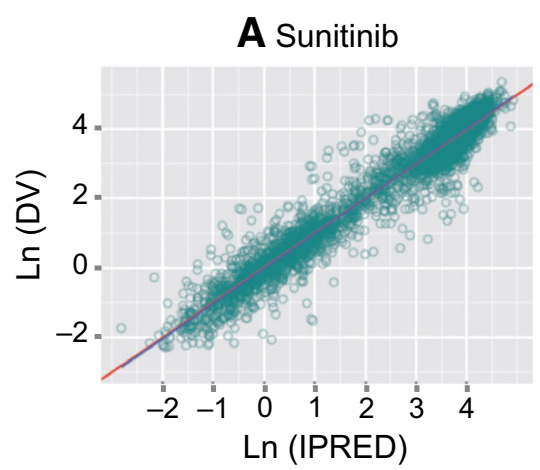

D Alanine aminotransferase

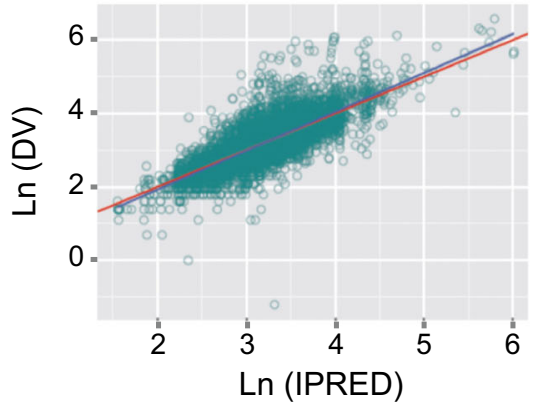

G Diastolic blood pressure

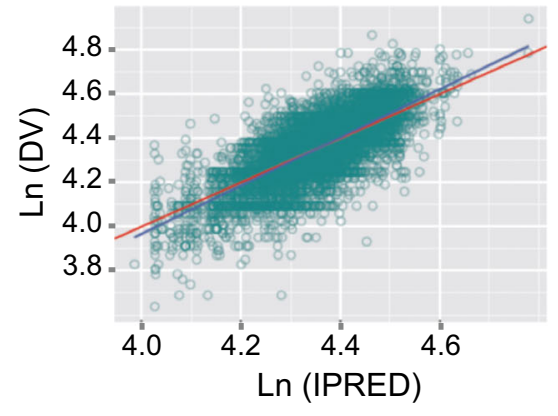

B SU12662

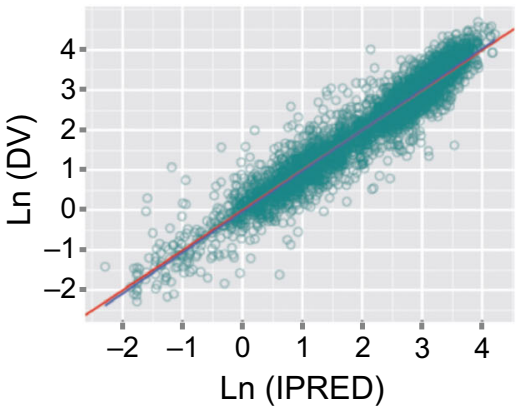

E Aspartate aminotransferase

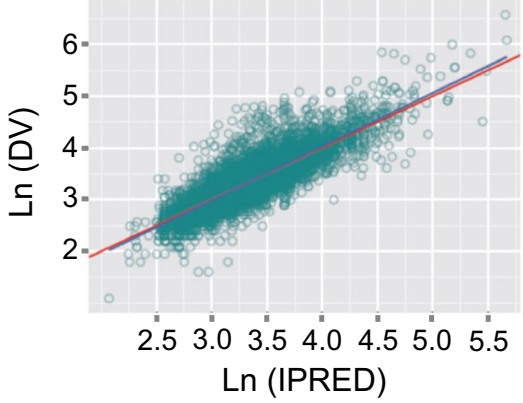

H Absolute neutrophil count

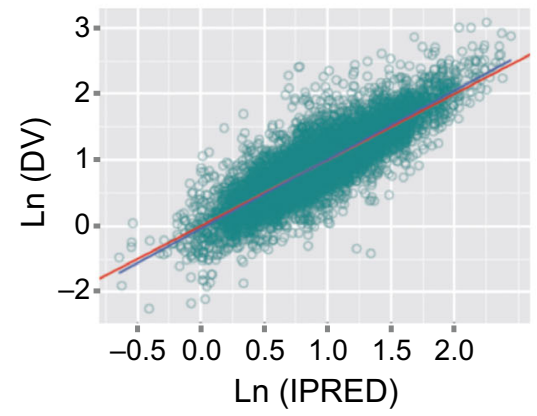

J Lymphocyte count

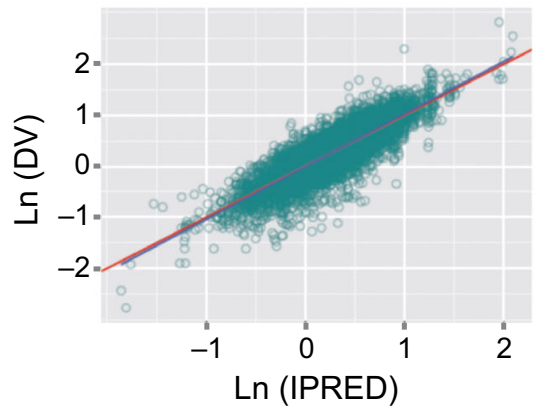

Sum of the longest diameter

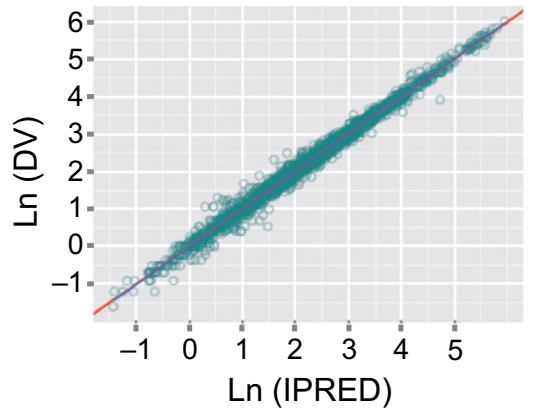

F Left ventricular ejection fraction
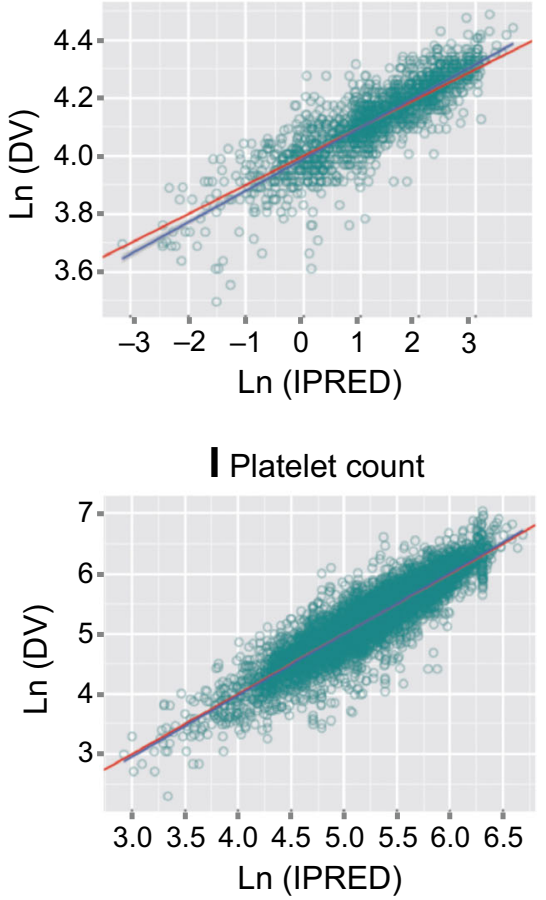

Fig. 1 Goodness-of-fit diagnostic plots for (a) plasma concentrations of sunitinib (final PK model); (b) plasma concentrations of the sunitinib active metabolite SU12662 (final PK model); (c) efficacy endpoint sum of longest diameter in target lesions (final PK/PD model); and (d-j) selected safety endpoints (final PK/PD model).
Solid red lines in DV versus IPRED plots are lines of unity. Solid blue lines are the PRED regression lines. $P D$ pharmacodynamic, $P K$ pharmacokinetic, $D V$ observed, IPRED individual predicted, PRED predicted 

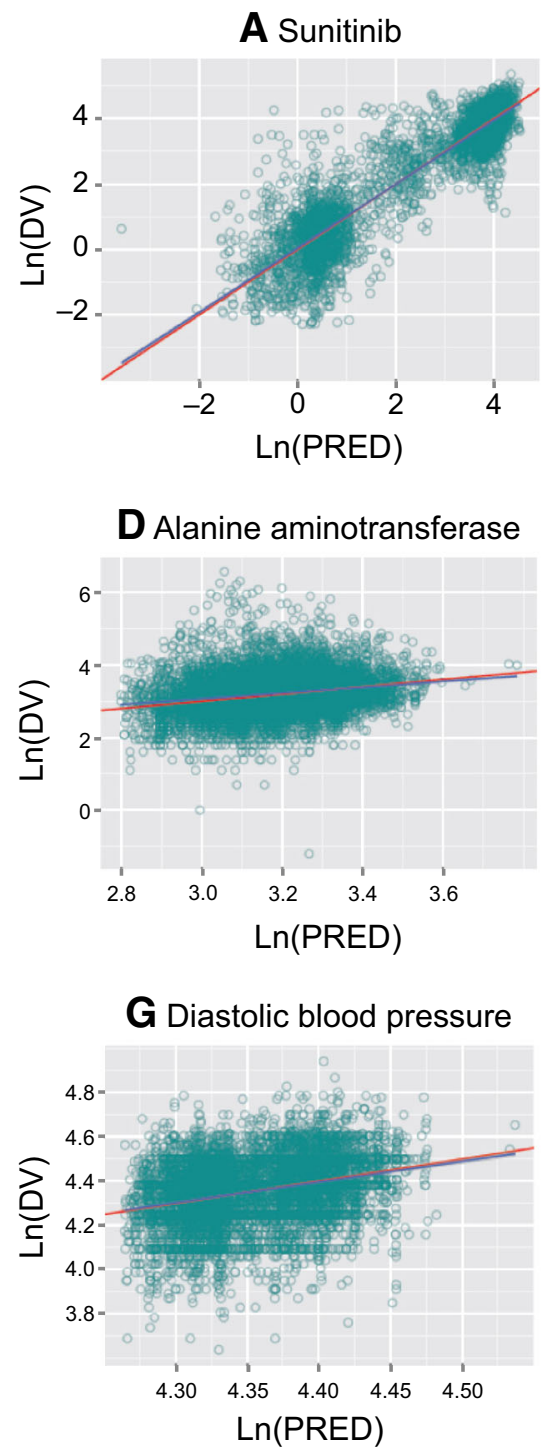

C Sum of the longest diameter

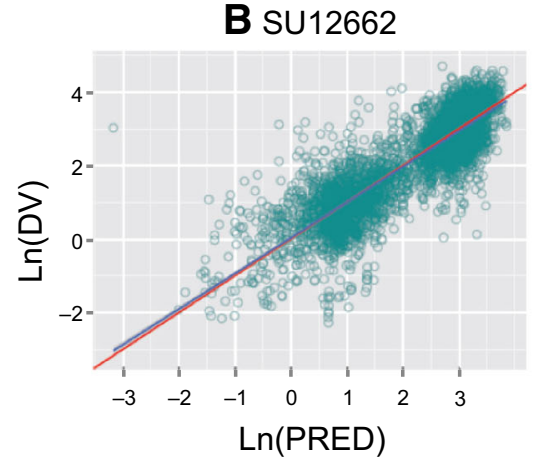

E Aspartate aminotransferase

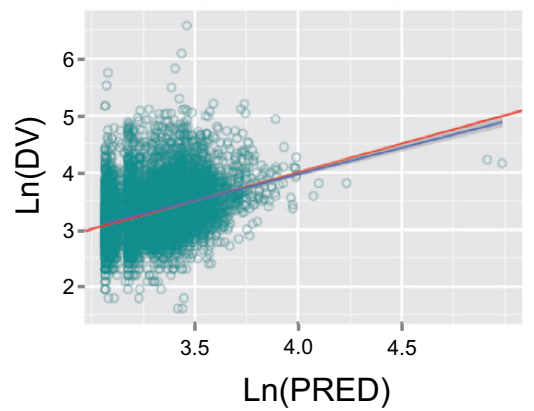

H Absolute neutrophil count
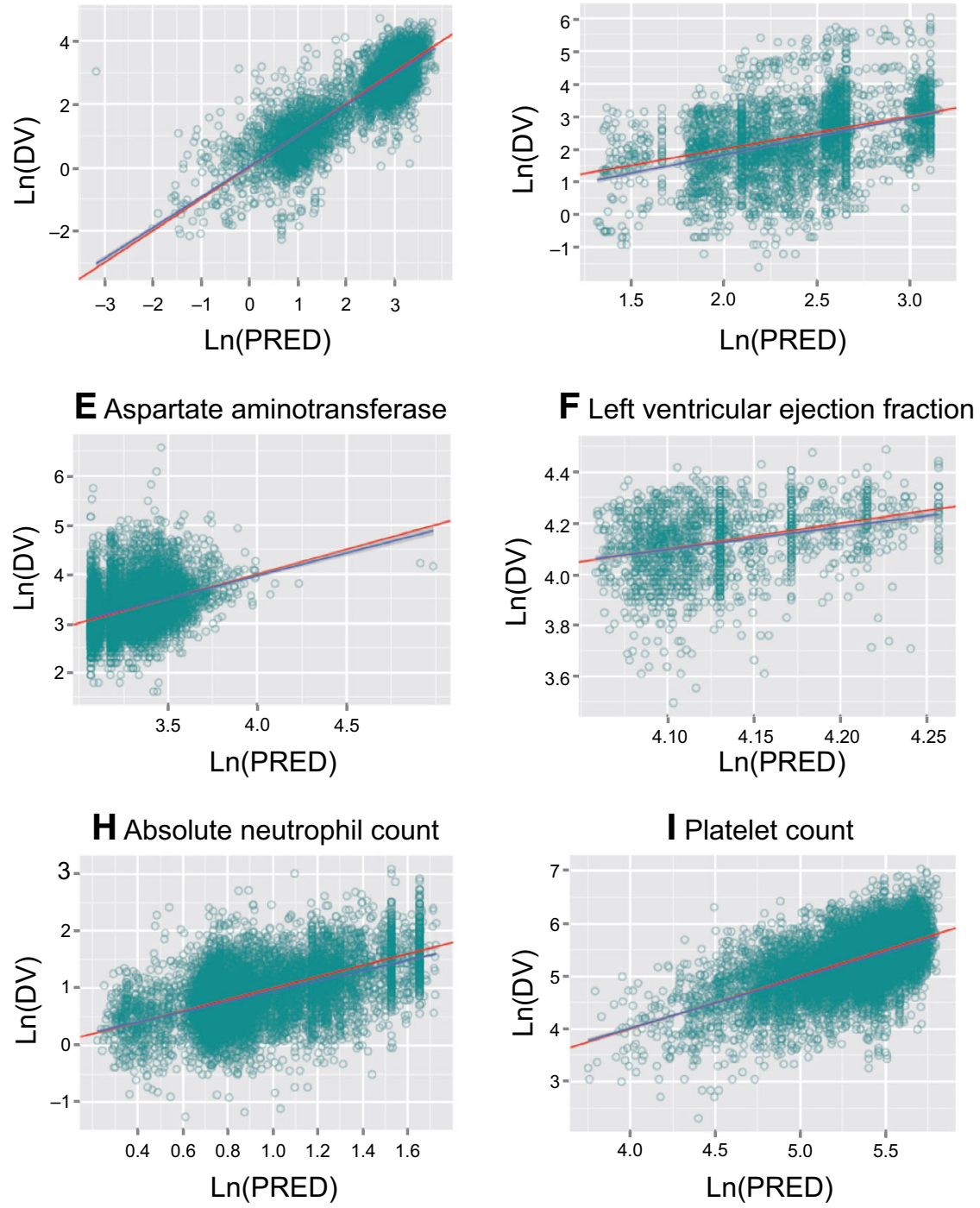

F Left ventricular ejection fraction

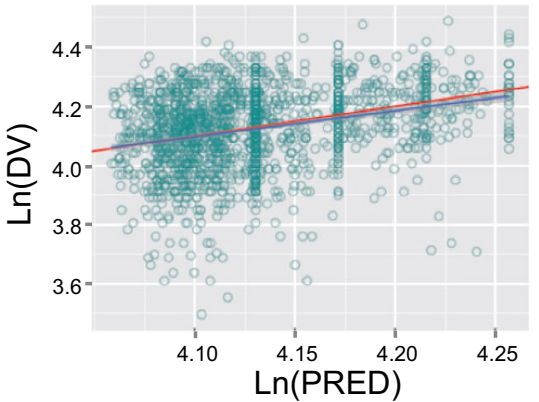

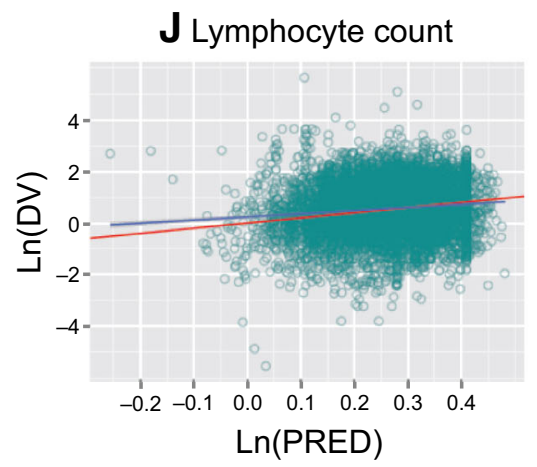




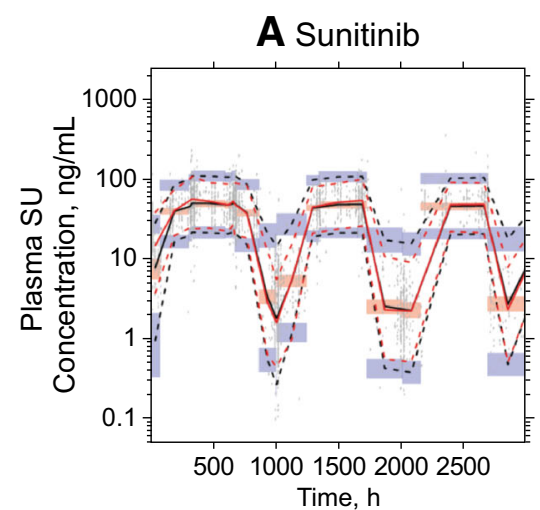

D Alanine aminotransferase

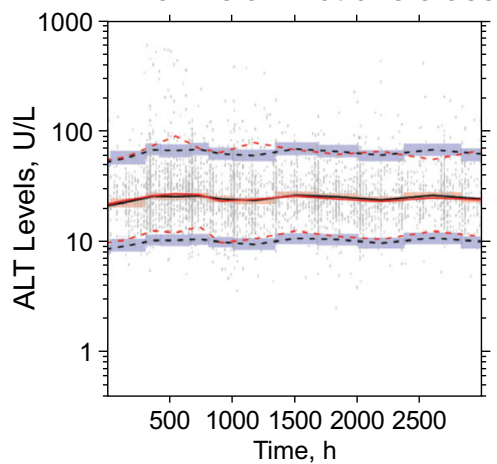

\section{G Diastolic blood pressure}

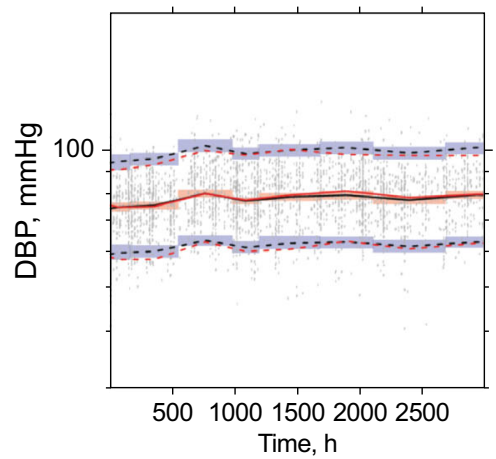

B SU012662

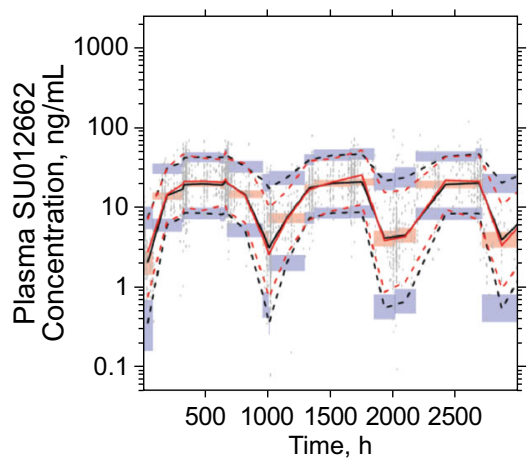

E Aspartate aminotransferase

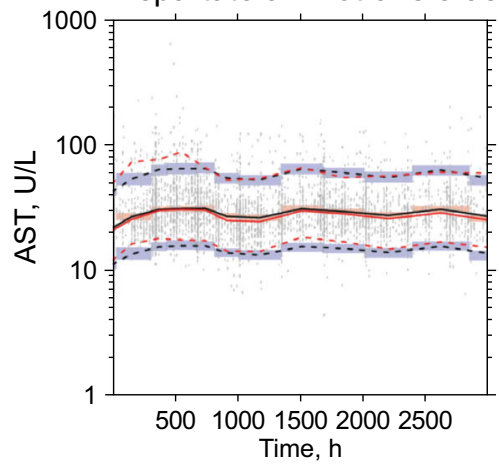

H Absolute neutrophil count

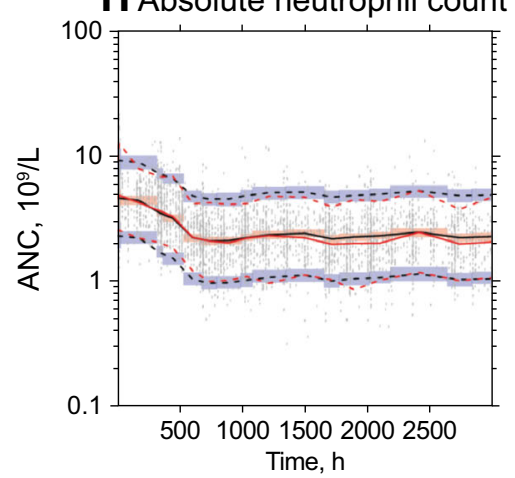

J Lymphocyte count

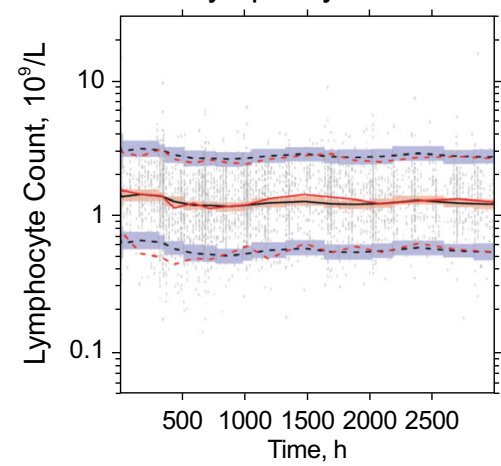

C Sum of the longest diameter

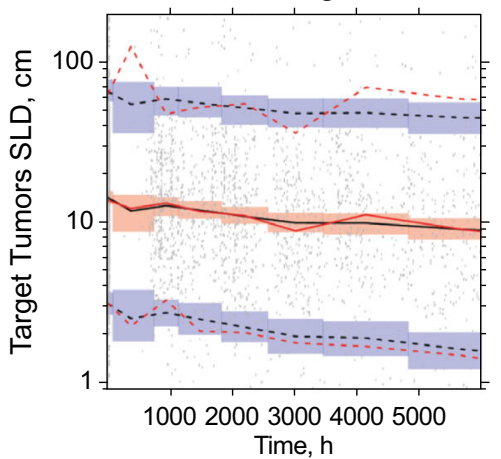

F Left ventricular ejection fraction
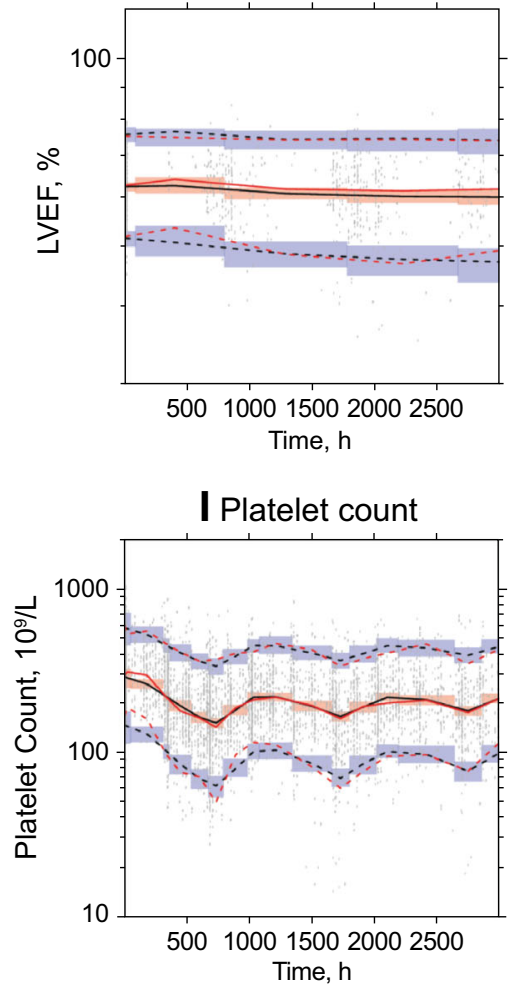

Fig. 3 Prediction and variance-corrected visual predictive check plot (final model) for (a) plasma concentrations of sunitinib; (b) plasma concentrations of the sunitinib active metabolite SU12662; (c) efficacy endpoint sum of longest diameter in target lesions; and $(\mathbf{d}-\mathbf{j})$ selected safety endpoints. ALT alanine aminotransferase, AST aspartate aminotransferase, $L V E F$ left ventricular ejection fraction, $D B P$ diastolic blood pressure, $A N C$ absolute neutrophil count 

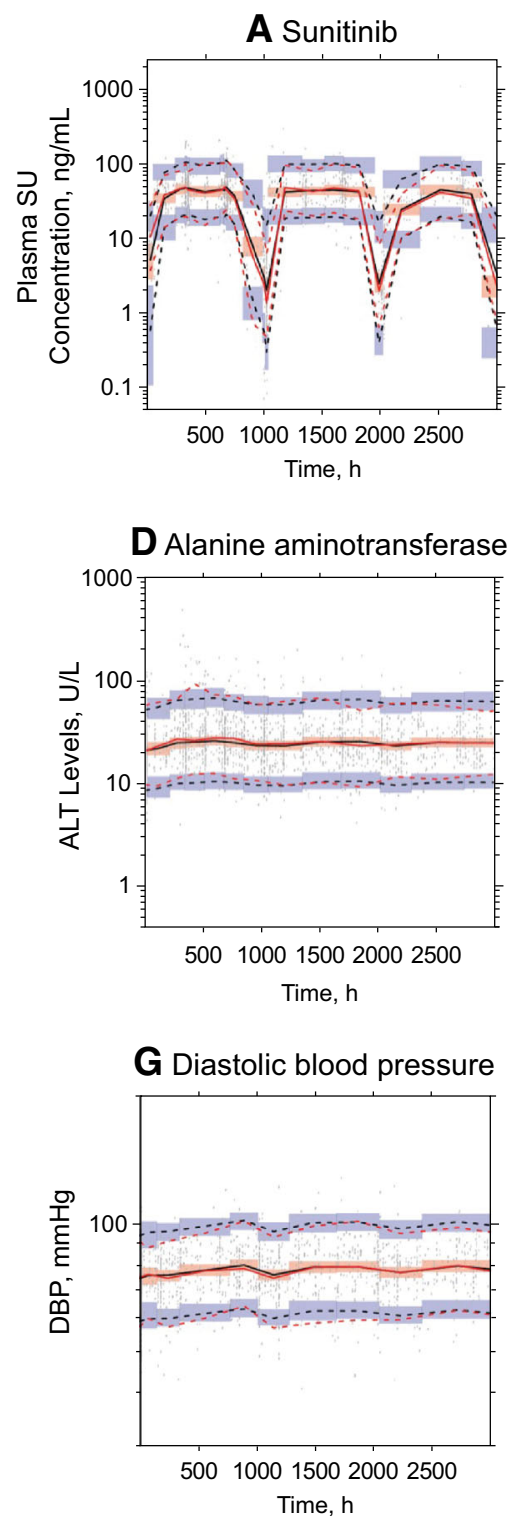
(validation data set) for (a) plasma concentrations of sunitinib; (b) plasma concentrations of the sunitinib active metabolite SU12662; (c) efficacy endpoint sum of longest diameter in target lesions; and
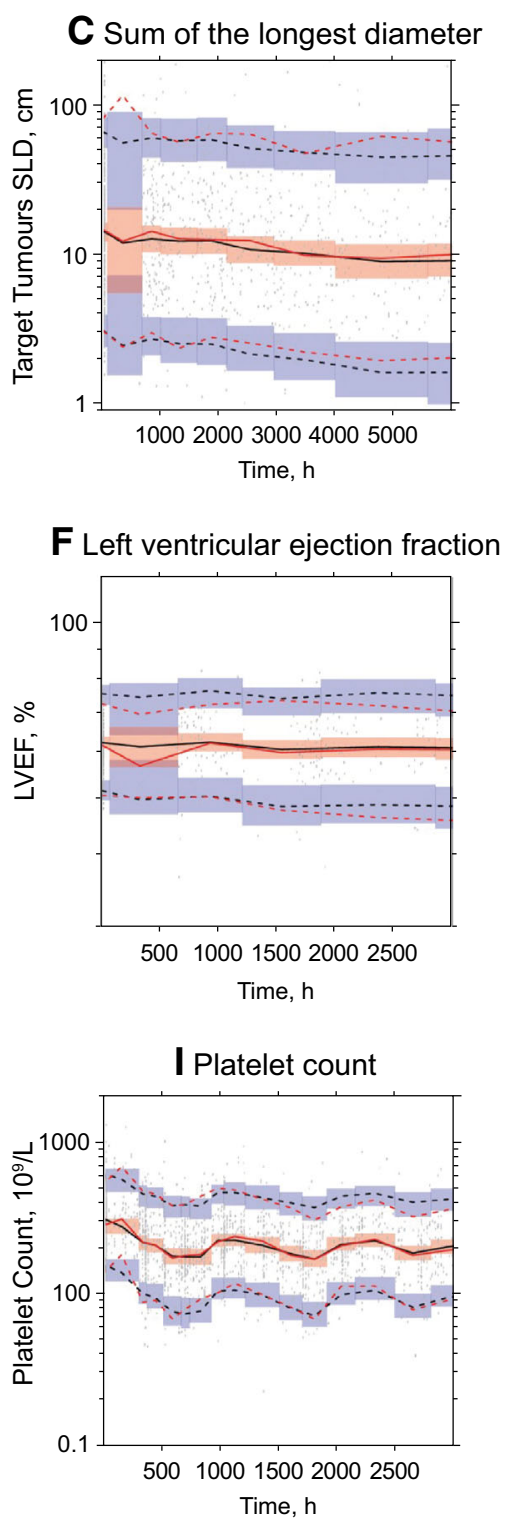

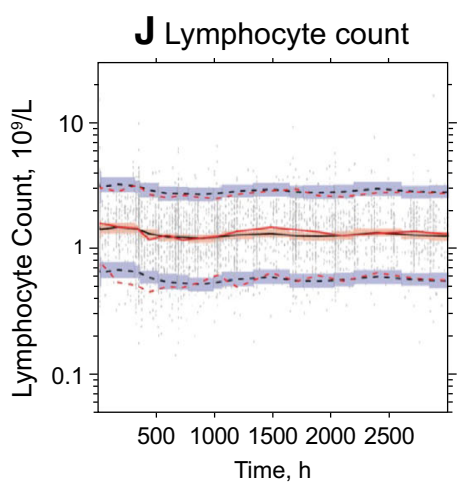

(d-j) selected safety endpoints. ALT alanine aminotransferase, AST aspartate aminotransferase, $L V E F$ left ventricular ejection fraction, $D B P$ diastolic blood pressure, $A N C$ absolute neutrophil count 
the model for SLD. Mean SLD at baseline was $14.3 \mathrm{~cm}$. Mean $K_{\text {out }}$ was $0.000267 \mathrm{~h}^{-1}$ and $E_{\max }$ was fixed to 1 . Mean concentration producing $50 \%$ of the maximum effect $\left(\mathrm{EC}_{50}\right)$ was $30.5 \mathrm{ng} / \mathrm{mL}$, and $K_{\text {tol }}$ was $0.0000141 \mathrm{~h}^{-1}$ (i.e. translating into a 5 and $10 \%$ decrease for $K_{\text {out }} \times$ $e^{- \text {Ktol } \times \text { time }}$ value in approximately 5 and 10 months, respectively).

PK/PD parameters with significant covariates effects in the final model were as shown in Eqs. 5, 6, and 7:

$$
\begin{aligned}
& \text { Baseline SLD }= 14.3 \times(1+0.574 \times \mathrm{BEC}) \\
& \times(1-0.348 \times \mathrm{RAC}) \\
& \times(1-0.43 \times \mathrm{SCH}) \\
& K_{\text {out }}=0.000267 \times(1+1.01 \times \mathrm{SCH}) \\
& \mathrm{EC}_{50}=30.5 \times(1+2.43 \times \mathrm{SCH}) \times(1+4.82 \times \mathrm{TUMR}) .
\end{aligned}
$$

Baseline SLD was higher with ECOG PS $\geq 1$ $(+57.4 \%)$, and lower with Asian ethnicity $(-34.8 \%)$ and Schedule CDD $(-43 \%) . K_{\text {out }}$ was higher for Schedule CDD $(+101 \%)$. In addition, EC $_{50}$ was higher for Schedule CDD $(+243 \%)$ and for patients with GIST (+482 \%). For the SLD models, goodness-of-fit diagnostic plots were generated, including individual predicted versus observed data (Fig. 1), population predicted versus observed data (Fig. 2), and weighted residuals versus time or predictions (Figs. S1and S2 of the ESM, respectively). Simulated predictions agreed well with observed data using VPC techniques for both the working and validation datasets (Figs. 3, 4, respectively). In addition, mean and $95 \%$ CI values generated by the models were consistent with those generated by bootstrapping (Table 3 ).

\subsubsection{Safety Endpoints}

$A L T$, AST, $L V E F$, and DBP: For the safety endpoints ALT, AST, LVEF, and DBP, a sequential PK/PD IDR model with first-order rate constant $\left(K_{\mathrm{PD}}\right)$ on $K_{\text {out }}$ (Fig. 5a) appeared to be the most parsimonious model with successful minimization, which met the diagnostic criteria. This model was therefore selected for these endpoints.

Mean (95 \% CI) ALT at baseline was $21.2(20.5-21.9)$ U/ L. For the ALT model, mean $(95 \% \mathrm{CI}) K_{\text {out }}$ and $K_{\mathrm{PD}}$ were $0.00916(0.00667-0.0116) \mathrm{h}^{-1}$ and $0.00401(0.00362-$ $0.00440) \mathrm{mL} / \mathrm{ng}$, respectively. BWT had a significant effect on baseline ALT and was modeled as per Eq. 8:

Baseline ALT $=21.2 \times(\mathrm{BWT} / 77.3)^{0.376}$.

Mean (95\% CI) AST at baseline was 21.5 (20.7-22.3) $\mathrm{U} / \mathrm{L}$, and, in the AST model, mean $(95 \% \mathrm{CI}) K_{\text {out }}$ and $K_{\mathrm{PD}}$ were $0.0142(0.0114-0.0170) \mathrm{h}^{-1}$ and $0.00572(0.00536-$ $0.00608) \mathrm{mL} / \mathrm{ng}$, respectively. Baseline AST was higher in patients with GIST $(+11.7 \%)$, as shown in Eq. 9:
Baseline AST $=21.5 \times(1+0.117 \times$ TUMR $)$.

$K_{\mathrm{PD}}$ for AST was higher in patients with baseline ECOG PS $\geq 1$ (BEC) $(+20 \%)$, and lower in patients with GIST $(-17.5 \%)$, as shown in Eq. 10:

$\begin{aligned} K_{\mathrm{PD}}= & 0.00572 \times(1+0.2 \times \mathrm{BEC}) \\ & \times(1-0.175 \times \mathrm{TUMR}) .\end{aligned}$

Mean $(95 \%$ CI) LVEF at baseline was $62.2 \%$ (61.2$63.2 \%)$. For the LVEF model, mean $(95 \% \mathrm{CI}) K_{\text {out }}$ and $K_{\mathrm{PD}}$ were $0.000656(0.000409-0.000903) \mathrm{h}^{-1}$ and 0.00131 (0.000965-0.00165) $\mathrm{mL} / \mathrm{ng}$, respectively. Baseline LVEF was higher in Asian patients $(+8.91 \%)$ and in females $(+4.21 \%)$, as shown in Eq. 11:

Baseline LVEF $=62.2 \times(1+0.0891 \times \mathrm{RAC})$

$$
\times(1+0.0421 \times \mathrm{SEX}) .
$$

Mean (95\% CI) DBP at baseline was 74.6 (74.0-75.2) mmHg. For the DBP model, mean $\left(95 \%\right.$ CI) $K_{\text {out }}$ and $K_{\mathrm{PD}}$ were $0.0288(0.0149-0.0427) \mathrm{h}^{-1}$ and $0.00184(0.00169$ $0.00199) \mathrm{mL} / \mathrm{ng}$, respectively. BWT significantly influenced baseline DBP, an effect that was modeled as per Eq. 12:

Baseline DBP $=74.6 \times(\mathrm{BWT} / 77.3)^{0.0691}$.

For the ALT, AST, LVEF, and DBP models, goodnessof-fit diagnostic plots were generated, including individual predicted versus observed data (Fig. 1), population predicted versus observed data (Fig. 2), and weighted residuals versus time or predictions (Figs. S1 and S2 of the ESM, respectively). Simulated predictions agreed well with observed data using VPC techniques for both the working and validation datasets (Figs. 3, 4, respectively). In addition, mean and $95 \% \mathrm{CI}$ values generated by the models were consistent with those generated by bootstrapping (Table 3).

$A N C, L C$, and $P C$ A sequential transit compartment in series with feedback loop (TCSFL) PK/PD model (Fig. 5b) with an $E_{\max }$ model effect on the proliferation rate constant of the endpoint in the proliferation compartment $\left(K_{\text {prol }}\right)$ in the stem cell compartment was used as the initial model for ANC, LC, and PC. Subsequently, a reduced model such as TCSFL with a $K_{\mathrm{PD}}$-type effect or simpler models were also examined. For ANC and PC, the initial model appeared to be the most parsimonious model and was thus selected. For LC, the reduced TCSFL model with a $K_{\mathrm{PD}^{-}}$type effect appeared to be the most parsimonious and was thus selected.

Mean (95\% CI) ANC at baseline was 4.61 (4.42$4.80) \times 10^{9} / \mathrm{L}$. For the ANC model, mean $(95 \% \mathrm{CI})$ transit time from the proliferation compartment to the circulation compartment (MTT), $E_{\max }, \mathrm{EC}_{50}$, power function for the rebound of feedback loop (POW), and power 
function for the sigmoidal $E_{\max }$ model (LAM) values were $182 \quad(177-187) \mathrm{h}, \quad 0.126 \quad(0.118-0.134), \quad 11.1 \quad(9.42-$ $12.8) \mathrm{ng} / \mathrm{mL}, 0.152(0.145-0.159)$, and 1.72 (1.41-2.03), respectively. ANC at baseline was lower in Asian patients $(-29.7 \%)$ and higher in patients with ECOG PS $\geq 1$ $(+13.4 \%)$, as shown in Eq. 13:

Baseline $\mathrm{ANC}=4.61 \times(1-0.297 \times \mathrm{RAC})$

$$
\times(1+0.134 \times \mathrm{BEC})
$$

Mean $(95 \% \mathrm{CI}) \mathrm{LC}$ at baseline was $1.51(1.44-1.58)$ $10 \% / \mathrm{L}$. For the LC model, mean $(95 \% \mathrm{CI}) \mathrm{MTT}, K_{\mathrm{PD}}$, and POW were 243 (226-260) h, 0.000687 (0.000603$0.000771) \mathrm{mL} / \mathrm{ng}$, and $0.200(0.183-0.217)$, respectively. LC at baseline was lower in patients with ECOG PS $\geq 1$ ($12.1 \%$ ), as shown in Eq. 14:

Baseline $\mathrm{LC}=1.51 \times(1-0.121 \times \mathrm{BEC})$.

MTT for LC was lower in Asian patients $(-39.8 \%)$ (Eq. 15):

MTT $=243 \times(1-0.398 \times$ RAC $)$.

$K_{\mathrm{PD}}$ for LC was lower in patients on the CDD schedule $(-41.7 \%)$ (Eq. 16):

$K_{\mathrm{PD}}=0.000687 \times(1-0.417 \times \mathrm{SCH})$.

Mean (95\% CI) PC at baseline was 297 (287-307) $10^{9} / \mathrm{L}$. For the PC model, mean $(95 \% \mathrm{CI}) \mathrm{MTT}, E_{\max }, \mathrm{EC}_{50}$, POW, and LAM were 88.4 (84.2-92.6) h, 0.154 (0.135$0.173), 65.0(60.0-70.0) \mathrm{ng} / \mathrm{mL}, 0.0895$ (0.0861-0.0929), and 3.09 (2.82-3.36), respectively. PC at baseline was lower with increasing BWT $(-0.327 \%$ per $\mathrm{kg})$ and in Asian patients (-25.5\%) (Eq. 17):

Baseline $\mathrm{PC}=297 \times(1-0.00327 \times(\mathrm{BWT}-77.3))$

$$
\times(1-0.255 \times \mathrm{RAC}) \text {. }
$$

MTT was higher in patients with ECOG PS $\geq 1$ $(+11.8 \%)$ and lower in Asian patients $(-19.5 \%)$ (Eq. 18):

MTT $=88.4 \times(1+0.118 \times \mathrm{BEC}) \times(1-0.195 \times \mathrm{RAC})$.

$E_{\max }$ was lower with increasing BWT $(-0.742 \%$ per kg) (Eq. 19):

$E_{\max }=0.154 \times(1-0.00742 \times(\mathrm{BWT}-77.3))$.

$\mathrm{EC}_{50}$ was lower in patients with GIST $(-10.8 \%)$ (Eq. 20):

$\mathrm{EC}_{50}=65.0 \times(1-0.108 \times \mathrm{TUMR})$.

For the ANC, LC, and PC models, goodness-of-fit diagnostic plots were generated, including individual predicted versus observed data (Fig. 1), population predicted versus observed data (Fig. 2), and weighted residuals versus time or predictions (Figs. S1 and S2 of the ESM, respectively). Simulated predictions agreed with observed data using VPC techniques for both the working and validation datasets (Figs. 3, 4). In addition, mean and $95 \%$ CI values from the model were similar to those generated by bootstrapping (Table 3 ).

\subsection{Patient Population Simulation}

\subsubsection{PK}

Trial simulations on the PK model for sunitinib and its metabolite were run to predict their concentrations in patients with advanced RCC when sunitinib was administered on Schedule 2/1 compared with Schedule 4/2 (Fig. 6). In these patients, mean (95\% CI) trough sunitinib concentrations during cycle 3 on Schedule $4 / 2$ and Schedule 2/1 were 42.6 (38.6-45.8) $\mathrm{ng} / \mathrm{mL}$ and 42.4 (40.4-44.1) ng/mL, respectively (Fig. 6a). Mean (95\% CI) trough SU12662 concentrations in RCC patients during cycle 3 on Schedule 4/2 and Schedule 2/1 were 19.7 (16.9-21.6) $\mathrm{ng} / \mathrm{mL}$ and $19.5(18.2-20.7) \mathrm{ng} / \mathrm{mL}$, respectively (Fig. 6c). The duration of time at maximum and minimum drug concentrations during the respective ontreatment and off-treatment periods within a 42-day cycle were shorter for Schedule 2/1 compared with Schedule 4/2 for both sunitinib and its metabolite (Fig. 6a, c). During the last day of the on-drug period, mean $(95 \% \mathrm{CI})$ sunitinib concentration on Schedule 4/2 and Schedule 2/1 was 67.3 (61.3-71.5) ng/mL and 65.5 (62-67.2) ng/mL, respectively (Fig. 6b). Mean (95\% CI) SU12662 concentration on this day was 29.5 (25.6-31.9) $\mathrm{ng} / \mathrm{mL}$ and 27.7 (25.7-28.9) ng/ $\mathrm{mL}$, respectively (Fig. 6d). Similar results were obtained for simulations with GIST patients (see the "Results" and Fig. S3 of the ESM).

\subsubsection{Efficacy Endpoint: Target Tumor Sum of the Largest Diameter}

Based on the final PK/PD efficacy model, trial simulations were performed to assess whether the predicted differences between the PK profiles of the two schedules had an impact on the efficacy of sunitinib in patients with advanced RCC. The endpoint used in this assessment was target tumor SLD (Fig. 7a). Based on the simulation results, median $(95 \%$ CI) SLD values at the end of cycle 6 for Schedule $4 / 2$ and Schedule 2/1 were $8.6(7.8-9.3) \mathrm{cm}$ and $8.2(7.4-8.8) \mathrm{cm}$, respectively. Furthermore, the simulated SLD values were then used to estimate PFS and ORR. The predicted median (95\% CI) PFS on Schedule 4/2 and Schedule 2/1 was 47.2 (30.9-54.6) weeks and 54.3 (35.1-59.9) weeks, respectively, while the predicted median $(95 \% \mathrm{CI})$ ORR on Schedule 4/2 and Schedule 2/1 was $27.0 \%$ (20.5-34.5) and 
Table 3 Summary of population parameter estimates in the final PK/PD models

\begin{tabular}{|c|c|c|c|c|}
\hline & \multicolumn{2}{|l|}{ Model results } & \multicolumn{2}{|l|}{ Bootstrap results } \\
\hline & Estimate $(95 \% \mathrm{CI})^{\mathrm{a}}$ & $\begin{array}{l}\text { Intersubject } \\
\text { variability } \\
(95 \% \mathrm{CI})^{\mathrm{a}}\end{array}$ & Estimate $(95 \% \mathrm{CI})^{\mathrm{a}}$ & $\begin{array}{l}\text { Intersubject } \\
\text { variability } \\
(95 \% \mathrm{CI})^{\mathrm{a}}\end{array}$ \\
\hline \multicolumn{5}{|l|}{ Efficacy endpoint } \\
\hline \multicolumn{5}{|c|}{ Tumor sum of longest diameters } \\
\hline BASE, $\mathrm{cm}$ & $14.3(12.9-15.7)$ & $91.7(86.7-96.4)$ & $14.6(12.8-16.5)$ & $91.5(85.6-97.7)$ \\
\hline$K_{\text {out }}, \mathrm{h}^{-1}$ & $0.000267(0.000224-0.00031)$ & $72.2(61.2-81.7)$ & $0.000270(0.000190-0.000330)$ & $81.6(66.3-95.9)$ \\
\hline$E_{\max }$ & 1 (FIXED) & - & 1 (FIXED) & - \\
\hline $\mathrm{EC}_{50}, \mathrm{ng} / \mathrm{mL}$ & $30.5(19.3-41.7)$ & $182(165-197)$ & $29.6(17.0-44.7)$ & $186(158-219)$ \\
\hline$K_{\mathrm{tol}}, \mathrm{h}^{-1}$ & $0.0000141(0.00000881-0.0000194)$ & $84.9(51.3-108)$ & $0.0000144(0.00000685-0.0000219)$ & $101(64.9-157)$ \\
\hline $\mathrm{BEC}$ on BASE & $0.574(0.321-0.827)$ & - & $0.546(0.352-0.822)$ & - \\
\hline RAC on BASE & $-0.348(-0.496$ to -0.200$)$ & - & $-0.361(-0.467$ to -0.241$)$ & - \\
\hline $\mathrm{SCH}$ on BASE & $-0.430(-0.531$ to -0.329$)$ & - & $-0.430(-0.505$ to -0.356$)$ & - \\
\hline $\mathrm{SCH}$ on $K_{\text {out }}$ & $1.01(0.557-1.46)$ & - & $1.26(0.383-2.45)$ & - \\
\hline $\mathrm{SCH}$ on $\mathrm{EC}_{50}$ & $2.43(0.901-3.96)$ & - & $2.60(1.10-5.46)$ & - \\
\hline TUMR on $\mathrm{EC}_{50}$ & $4.82(2.15-7.49)$ & - & $4.72(2.32-8.70)$ & - \\
\hline Residual variability, $\%$ & $14.3(14.1-14.5)$ & - & $14.2(12.4-15.8)$ & - \\
\hline \multicolumn{5}{|l|}{ Safety endpoints } \\
\hline \multicolumn{5}{|l|}{ Platelets } \\
\hline BASE, $10^{9} / \mathrm{L}$ & $297(287-307)$ & $34.4(32.1-36.4)$ & $297(285-308)$ & $34.2(32.2-36.6)$ \\
\hline MTT, h & $88.4(84.2-92.6)$ & $22.1(19.7-24.3)$ & $88.1(66.4-107)$ & $21.9(16.6-35.9)$ \\
\hline$E_{\max }$ & $0.154(0.135-0.173)$ & $26.6(20.1-31.8)$ & $0.156(0.103-0.304)$ & $26.8(16.4-34.6)$ \\
\hline $\mathrm{EC}_{50}, \mathrm{ng} / \mathrm{mL}$ & $65.0(60.0-70.0)$ & $21.1(18.0-23.8)$ & $66.0(55.1-110)$ & $21.2(16.7-25.4)$ \\
\hline POW & $0.0895(0.0861-0.0929)$ & - & $0.0898(0.0638-0.117)$ & - \\
\hline LAM & $3.09(2.82-3.36)$ & - & $3.01(2.13-3.98)$ & - \\
\hline BWT on BASE & $-0.00327(-0.00473$ to -0.00181$)$ & - & $-0.00326(-0.0045$ to -0.00153$)$ & - \\
\hline RAC on BASE & $-0.255(-0.321$ to -0.189$)$ & - & $-0.253(-0.315$ to -0.197$)$ & - \\
\hline BEC on MTT & $0.118(0.0474-0.189)$ & - & $0.118(0.0495-0.244)$ & - \\
\hline RAC on MTT & $-0.195(-0.249$ to -0.141$)$ & - & $-0.189(-0.260$ to -0.0921$)$ & - \\
\hline BWT on $E_{\max }$ & $-0.00742(-0.00935$ to -0.00549$)$ & - & $-0.00752(-0.00962$ to -0.00553$)$ & - \\
\hline TUMR on $\mathrm{EC}_{50}$ & $-0.108(-0.155$ to -0.0606$)$ & - & $-0.104(-0.160$ to -0.0548$)$ & - \\
\hline Residual variability, $\%$ & $24.0(23.9-24.1)$ & - & $24.0(22.8-25.2)$ & - \\
\hline \multicolumn{5}{|l|}{ ANC } \\
\hline BASE, $10^{9} / \mathrm{L}$ & $4.61(4.42-4.80)$ & $30.6(28.5-32.7)$ & $4.62(4.43-4.82)$ & $30.5(28.1-32.7)$ \\
\hline MTT, h & $182(177-187)$ & $16.3(13.8-18.4)$ & $183(172-192)$ & $15.9(12.8-20.3)$ \\
\hline$E_{\max }$ & $0.126(0.118-0.134)$ & $17.3(13.7-20.3)$ & $0.127(0.108-0.211)$ & $17.3(11.8-21.3)$ \\
\hline $\mathrm{EC}_{50}, \mathrm{ng} / \mathrm{mL}$ & $11.1(9.42-12.8)$ & $84.3(75.0-92.7)$ & $11.8(6.61-25.9)$ & $82.6(48.8-120)$ \\
\hline POW & $0.152(0.145-0.159)$ & - & $0.151(0.129-0.180)$ & - \\
\hline LAM & $1.72(1.41-2.03)$ & - & $1.74(0.679-3.25)$ & - \\
\hline $\mathrm{BEC}$ on BASE & $0.134(0.070-0.198)$ & - & $0.136(0.0680-0.192)$ & - \\
\hline RAC on BASE & $-0.297(-0.351$ to -0.243$)$ & - & $-0.294(-0.350$ to -0.236$)$ & - \\
\hline Residual variability, $\%$ & $28.9(28.7-29.1)$ & - & $28.9(27.8-30.1)$ & - \\
\hline \multicolumn{5}{|l|}{ AST } \\
\hline BASE, U/L & $21.5(20.7-22.3)$ & $31.8(30.2-33.3)$ & $21.6(20.6-22.5)$ & $31.9(28.7-35.1)$ \\
\hline$K_{\text {out }}, \mathrm{h}^{-1}$ & $0.0142(0.0114-0.0170)$ & $120(105-133)$ & $0.0139(0.0108-0.0161)$ & $121(94.9-141)$ \\
\hline$K_{\mathrm{PD}}, \mathrm{mL} / \mathrm{ng}$ & $0.00572(0.00536-0.00608)$ & $33.8(31.0-36.3)$ & $0.00557(0.00498-0.00600)$ & $40.8(31.4-49.6)$ \\
\hline TUMR on BASE & $0.117(0.0564-0.178)$ & - & $0.100(0.0284-0.175)$ & - \\
\hline BEC on $K_{\mathrm{PD}}$ & $0.200(0.0928-0.307)$ & - & $0.211(0.0813-0.367)$ & - \\
\hline
\end{tabular}


Table 3 continued

\begin{tabular}{|c|c|c|c|c|}
\hline & \multicolumn{2}{|l|}{ Model results } & \multicolumn{2}{|l|}{ Bootstrap results } \\
\hline & Estimate $(95 \% \mathrm{CI})^{\mathrm{a}}$ & $\begin{array}{l}\text { Intersubject } \\
\text { variability } \\
(95 \% \mathrm{CI})^{\mathrm{a}}\end{array}$ & Estimate $(95 \% \mathrm{CI})^{\mathrm{a}}$ & $\begin{array}{l}\text { Intersubject } \\
\text { variability } \\
(95 \% \mathrm{CI})^{\mathrm{a}}\end{array}$ \\
\hline TUMR on $K_{\mathrm{PD}}$ & $-0.175(-0.256$ to -0.0941$)$ & - & $-0.121(-0.231$ to 0.00935$)$ & - \\
\hline Residual variability, $\%$ & $25.7(25.6,25.8)$ & - & $26.0(24.9-27.3)$ & - \\
\hline \multicolumn{5}{|l|}{ ALT } \\
\hline BASE, U/L & $21.2(20.5-21.9)$ & $40.5(38.2-42.7)$ & $21.2(20.5-22.1)$ & $40.2(37.4-43.6)$ \\
\hline$K_{\text {out }}, \mathrm{h}^{-1}$ & $0.00916(0.00667-0.0116)$ & $128(102-150)$ & $0.00937(0.00676-0.0126)$ & $126(72.2-175)$ \\
\hline$K_{\mathrm{PD}}, \mathrm{mL} / \mathrm{ng}$ & $0.00401(0.00362-0.00440)$ & $57.0(52.3-61.3)$ & $0.00400(0.00347-0.00449)$ & $57.2(41.8-71.6)$ \\
\hline BWT on BASE & $0.376(0.238-0.514)$ & - & $0.375(0.226-0.498)$ & - \\
\hline Residual variability, $\%$ & $37.3(37.1-37.5)$ & - & $37.3(35.1-39.2)$ & - \\
\hline \multicolumn{5}{|l|}{ Lymphocyte count } \\
\hline BASE, $10^{9} / \mathrm{L}$ & $1.51(1.44-1.58)$ & $40.2(38.2-42.2)$ & $1.50(1.46-1.56)$ & $40.2(37.4-43.4)$ \\
\hline MTT, h & $243(226-260)$ & $28.2(23.7-32.0)$ & $247(223-265)$ & $26.8(14.8-40.0)$ \\
\hline$K_{\mathrm{PD}}, \mathrm{mL} / \mathrm{ng}$ & $0.000687(0.000603-0.000771)$ & $65.6(56.7-73.3)$ & $0.000677(0.000523-0.000817)$ & $70.5(53.2-87.3)$ \\
\hline POW & $0.200(0.183-0.217)$ & - & $0.211(0.138-0.286)$ & - \\
\hline BEC on BASE & $-0.121(-0.180$ to -0.0620$)$ & - & $-0.121(-0.192$ to -0.0523$)$ & - \\
\hline RAC on MTT & $-0.398(-0.457$ to -0.339$)$ & - & $-0.417(-0.572$ to -0.154$)$ & - \\
\hline $\mathrm{SCH}$ on $K_{\mathrm{PD}}$ & $-0.417(-0.555$ to -279$)$ & - & $-0.371(-0.616$ to -0.132$)$ & - \\
\hline Residual variability, $\%$ & $25.4(25.2-25.6)$ & - & $25.4(24.6-26.2)$ & - \\
\hline \multicolumn{5}{|c|}{ Left ventricular ejection fraction } \\
\hline BASE, $\%$ & $62.2(61.2-63.2)$ & $8.61(7.49-9.60)$ & $61.9(60.7-62.9)$ & $8.53(7.46-9.37)$ \\
\hline$K_{\text {out }}, \mathrm{h}^{-1}$ & $0.000656(0.000409-0.000903)$ & $82.8(0.0-119)$ & $0.000458(0.0000783-0.0147)$ & $128(57.7-266)$ \\
\hline$K_{\mathrm{PD}}, \mathrm{mL} / \mathrm{ng}$ & $0.00131(0.000965-0.00165)$ & $90.1(67.3-108)$ & $0.00139(0.000649-0.0026)$ & $104(59.4-149)$ \\
\hline RAC on BASE & $0.0891(0.0568-0.121)$ & - & $0.0852(0.0598-0.107)$ & - \\
\hline SEX on BASE & $0.0421(0.0184-0.0658)$ & - & $0.0454(0.0195-0.0681)$ & - \\
\hline Residual variability, $\%$ & $7.89(7.74-8.04)$ & - & $8.27(7.39-8.99)$ & - \\
\hline \multicolumn{5}{|l|}{ Diastolic blood pressure } \\
\hline BASE, $\mathrm{mmHg}$ & $74.6(74.0-75.2)$ & $9.38(8.77-10.0)$ & $74.5(73.8-75.2)$ & $9.36(8.62-10.0)$ \\
\hline$K_{\text {out }}, \mathrm{h}^{-1}$ & $0.0288(0.0149-0.0427)$ & $108(52.7-143)$ & $0.0290(0.0140-0.0508)$ & $106(37.4-181)$ \\
\hline$K_{\mathrm{PD}}, \mathrm{mL} / \mathrm{ng}$ & $0.00184(0.00169-0.00199)$ & $47.6(39.0-54.9)$ & $0.00185(0.00169-0.00207)$ & $47.7(38.5-55.3)$ \\
\hline BWT on BASE & $0.0691(0.0383-0.0999)$ & - & $0.0707(0.0373-0.104)$ & - \\
\hline Residual variability, $\%$ & $10.4(10.3-10.5)$ & - & $10.4(10.0-10.7)$ & - \\
\hline
\end{tabular}

$A L T$ alanine aminotransferase, $A N C$ absolute neutrophil count, $A S T$ aspartate aminotransferase, $B A S E$ baseline, $B E C$ baseline Eastern Cooperative Oncology Group performance status, $B W T$ baseline weight, $C I$ confidence interval, $E C_{50}$ drug concentration achieving $50 \%$ of the maximum effect, $E_{\max }$ maximum drug effect, $K_{\text {out }}$ output elimination rate constant, $K_{P D}$ first-order rate constant, $K_{\text {tol }}$ tolerance function, $L A M$ power function for the sigmoidal $E_{\max }$ model, $M T T$ mean transit time from the proliferation compartment to the circulation compartment, $P D$ pharmacodynamic, $P K$ pharmacokinetic, $P O W$ power function for the rebound feedback loop, $R A C$ race, $S C H$ dosing schedule, $S E$ standard error, TUMR tumor

a $95 \%$ CI was estimated as (mean $-1.96 \times \mathrm{SE}-$ mean $+1.96 \times \mathrm{SE})$

$31.0 \%$ (21.9-40.5), respectively. The differences between these two schedules in predicted efficacy outcomes in patients with advanced RCC were not considered clinically relevant. Similar predictions were obtained for GIST patients, such that the decrease in SLD and TTP slightly favored Schedule 2/1, although differences in these outcomes were not clinically relevant. No difference in ORR was observed between schedules in GIST patients (see the Results section and Fig. S4 of the ESM).

\subsubsection{Safety Endpoints}

Based on the final PK/PD safety models, trial simulations were performed for each of the endpoints to assess whether the predicted differences between the PK profiles of the two schedules had any impact on the selected safety endpoints in patients with advanced RCC. The simulation results indicated that the overall effect of sunitinib on the selected safety endpoints was similar 

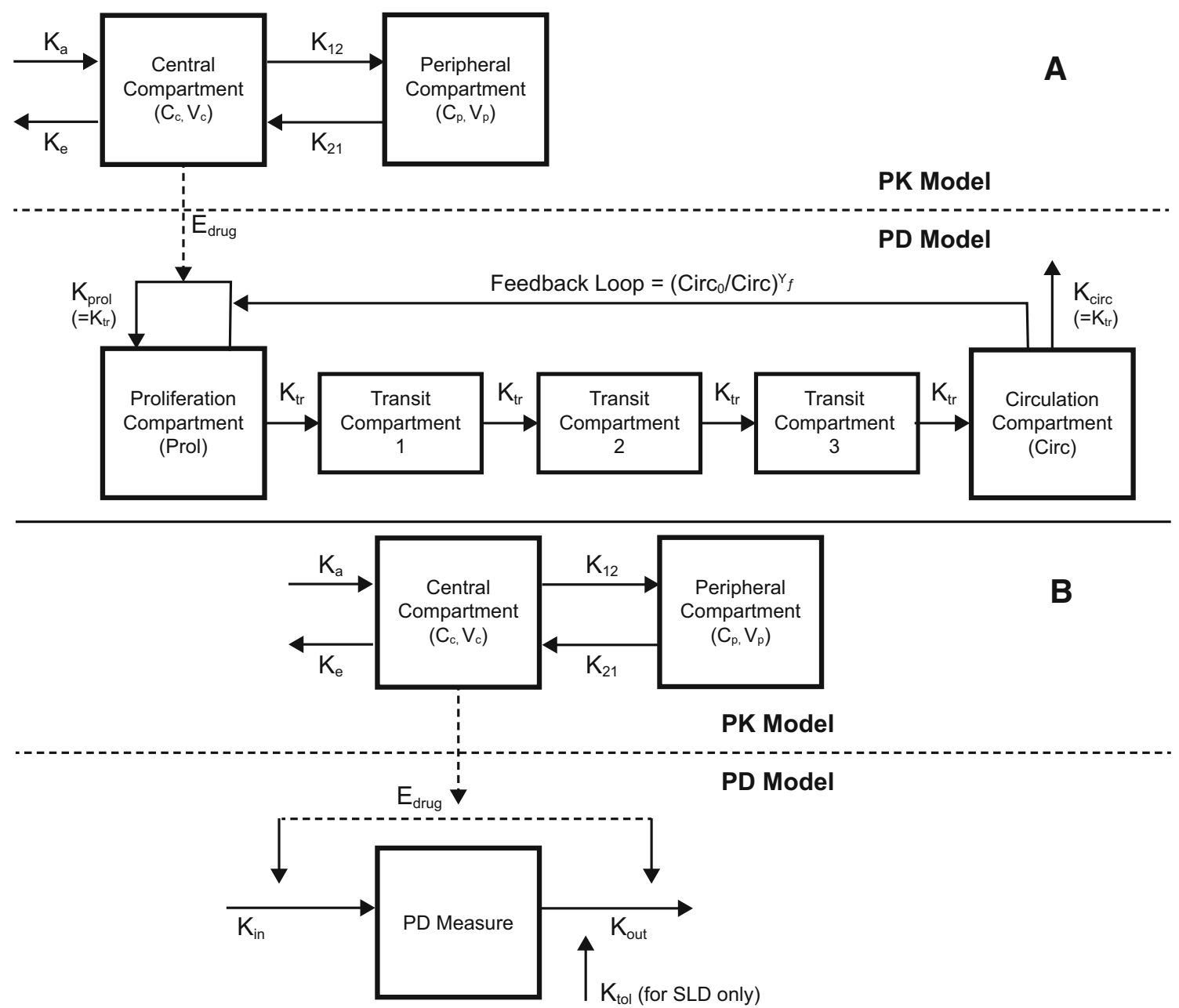

Fig. 5 Schematics of the (a) mechanism-based PK/PD model, an indirect response model, and (b) semi-mechanistic PK/PD model with transit compartments in series plus a rebound feedback loop. $C_{c}$ drug concentration in the central compartment, $C_{p}$ drug concentration in the peripheral compartment, Circ effect concentration in the circulation compartment, $E_{d r u g}$ drug effect calculated using a basic or sigmoidal maximum effect model, $\gamma_{f}$ feedback loop power function, $K_{a}$ drug absorption rate constant, $K_{e}$ drug elimination rate constant, $K_{\text {in }}$ input rate constant, $K_{\text {out }}$ output (elimination) rate constant, $K_{\text {circ }}$ elimination rate constant of the endpoint from the circulation

between Schedules $4 / 2$ and $2 / 1$, with the exception of $\mathrm{PC}$, for which Schedule 2/1 was associated with a significantly lower incidence of grades 3 and 4 thrombocytopenic events than Schedule 4/2 (9 vs. $16 \%$; Fig. 7bh). Additionally, median (95\% CI) PC nadir values during cycle 3 were significantly higher for Schedule 2/1 compared with Schedule 4/2 (119 [112-128] vs. 104 [94-114] $\left.\times 10^{3} / \mu \mathrm{L}\right)$, further supporting the predicted lower incidence rate of grades 3 and 4 thrombocytopenic events for Schedule 2/1 in patients with advanced RCC (Fig. 7b). Similar predictions were obtained for GIST patients (see the Results section and Fig. S4 of the ESM). compartment, $K_{\text {prol }}$ proliferation rate constant of the endpoint in the proliferation compartment (e.g. stem cells), $K_{t o l}$ tolerance function, $K_{t r}$ transit rate constant, $K_{12}$ drug distribution rate constant from central to peripheral compartment, $K_{21}$ drug redistribution rate constant from peripheral to central compartment, $P D$ pharmacodynamic, $P K$ pharmacokinetic, $P r o l$ effect concentration in proliferation compartment, $S L D$ sum of the largest diameter, $V_{c}$ drug central compartment volume of distribution, $V_{p}$ drug peripheral compartment volume of distribution

\section{Discussion}

In this analysis, PK/PD models predicting the effects of sunitinib on the efficacy endpoint SLD and on several safety endpoints were generated. The models predicted that, in patients with advanced RCC or GIST, sunitinib Schedule $2 / 1$ dosing would have the same efficacy as Schedule 4/2, despite some differences in the PK profiles of the two schedules. The models also predicted that, in both indications, sunitinib-related thrombocytopenia would be less severe on Schedule 2/1 versus Schedule 4/2. The findings from our study are supported by several retrospective studies [11-14] and by prospective studies [26, 
A
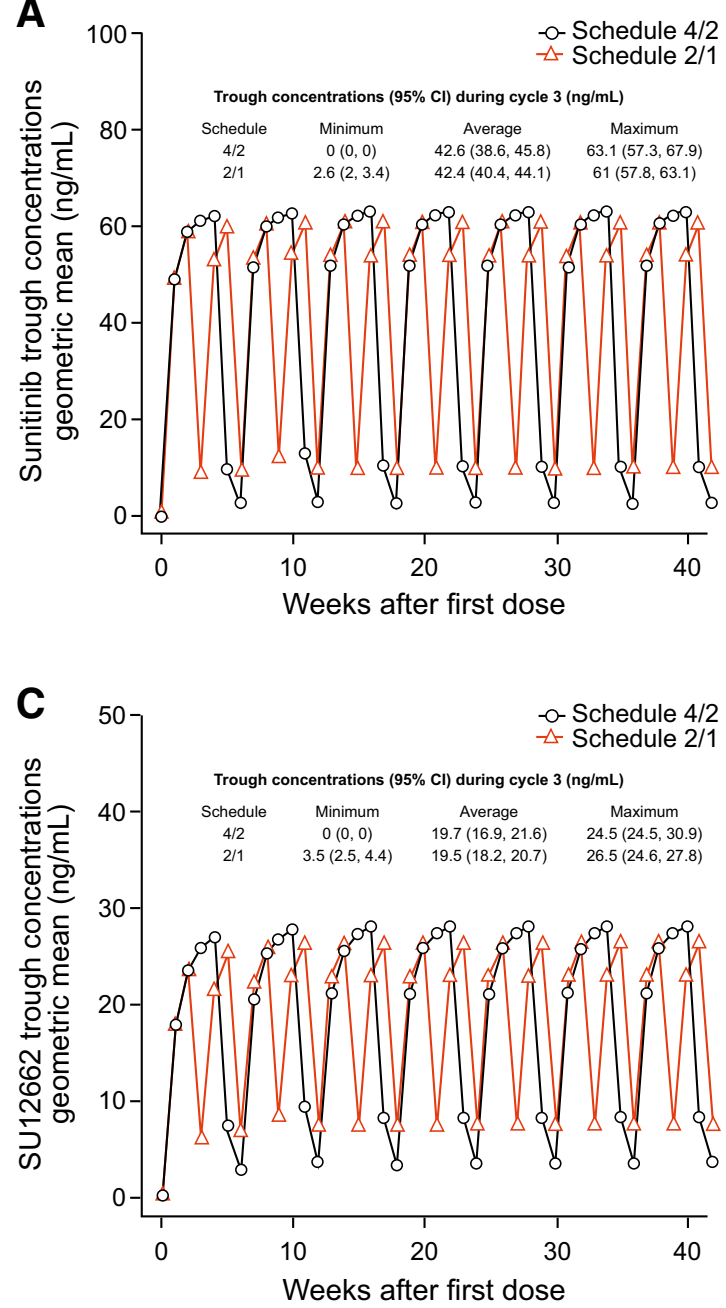

Fig. 6 Trial simulations predicted mean PK profiles and median (95\% CI) PK parameters during (a, c) cycle 3, following weekly trough PK assessments, and (b, d) the last day of the on-drug period, following PK assessments every $3 \mathrm{~h}$, for sunitinib and SU12662 in

27]. In addition, a prospective phase II trial of sunitinib Schedule $4 / 2$ versus Schedule $2 / 1$ as first-line therapy in metastatic RCC is ongoing (NCT02398552) and, once completed, could support the findings of the PK/PD modeling.

However, one of the limitations of these types of PK/PD models was that they required continuous safety measures/ endpoints; therefore, categorical safety endpoints, such as hand-foot syndrome, fatigue, nausea, vomiting, or diarrhea, could not be included in the PK/PD modeling analyses. In addition, considering the similarities in the dose, total dose, the average and steady-state plasma exposures over any cycle (i.e. 6-week period) between the two dosing schedules, the empirical models such as time to event models or Markov-type models, would not be able to differentiate between the two dosing schedules and hence could not be utilized with respect to these categorical
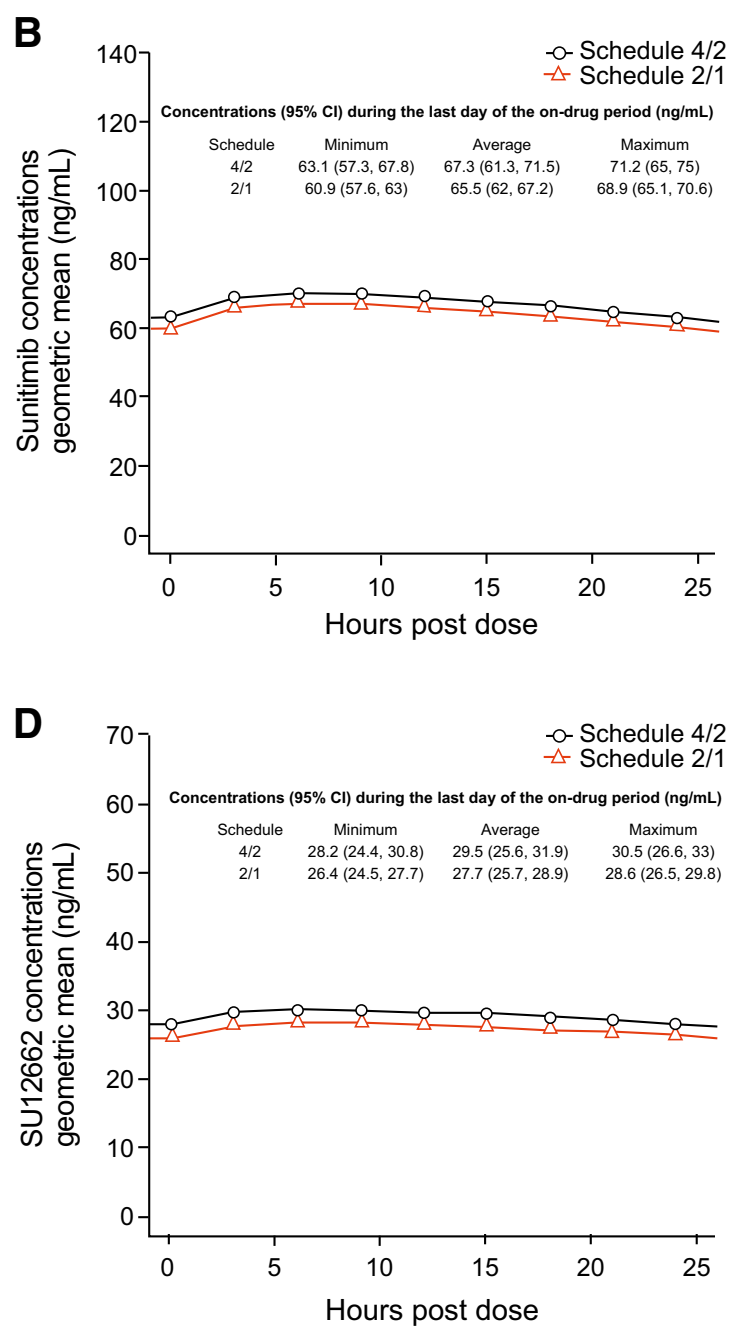

patients with advanced RCC receiving sunitinib $50 \mathrm{mg} /$ day on Schedule $4 / 2$ (4 weeks on followed by 2 weeks off treatment) or Schedule 2/1 (2-weeks-on followed by 1-week-off treatment). CI confidence interval, $P K$ pharmacokinetic, $R C C$ renal cell carcinoma

safety endpoints. That said, prospective clinical studies have shown that other categorical AEs, including fatigue, hand-foot syndrome, stomatitis, and dysgeusia, improved by changing from Schedule 4/2 to Schedule 2/1 [11,27]. Another limitation of the model was that efficacy was evaluated in patients with advanced RCC using the target tumor SLD rather than PFS or overall survival. However, SLD has been shown to be a reliable predictor of outcome in RCC patients receiving vascular endothelial growth factor-targeted therapies [28, 29].

The models generated here were based on a clinical dataset with few patients treated on sunitinib Schedule 2/1 or $2 / 2$. Therefore, for the covariate analyses, with respect to the effect of dosing schedule on different PK or PK/PD parameters, intermittent Schedules 2/2, 2/1, and 4/2 were grouped together and compared with CDD schedules. Grouping of the intermittent dosing schedules was also 
Fig. 7 Trial simulations predicted mean profiles and median $(95 \% \mathrm{CI})$ values for (a) efficacy, and (b-h) safety endpoints in patients with advanced RCC receiving sunitinib $50 \mathrm{mg} /$ day on Schedule 4/2 (4-weeks-on followed by 2 -weeks-off treatment) or Schedule 2/1 (2weeks-on followed by 1 -weekoff treatment), with corresponding predictions for ORR and PFS and adverse event incident rates, following assessments made twice every 6 weeks. $C I$ confidence interval, $G$ grade of AE intensity, ORR objective response rate, $P F S$ progression-free survival, $R C C$ renal cell carcinoma
A Sum of longest diameter (SLD)

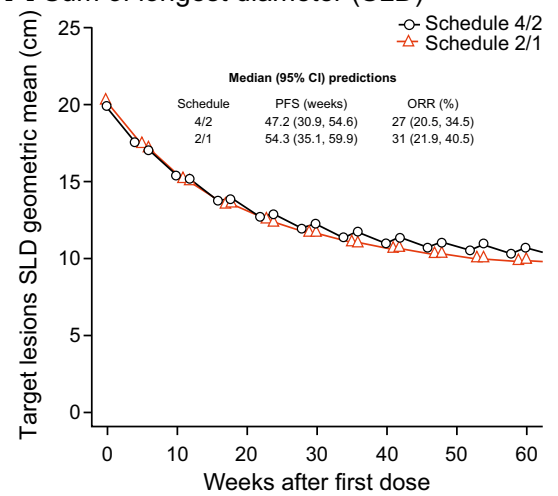

C Left ventricular ejection fraction

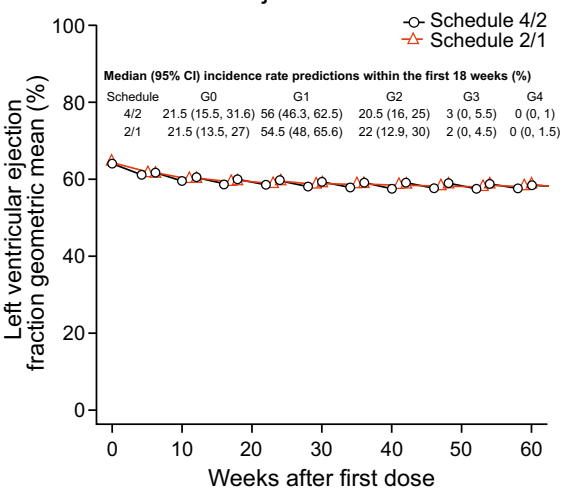

E Alanine aminotransferase (ALT)

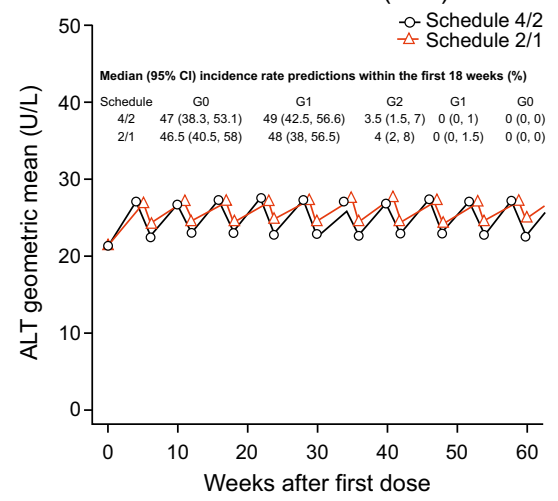

G Aspartate aminotransferase (AST)

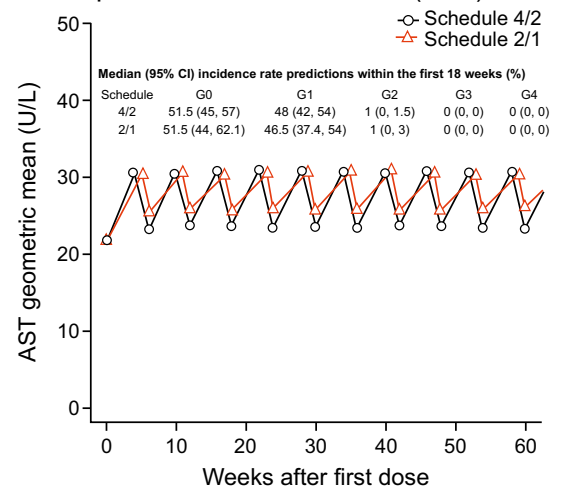

B Platelet count

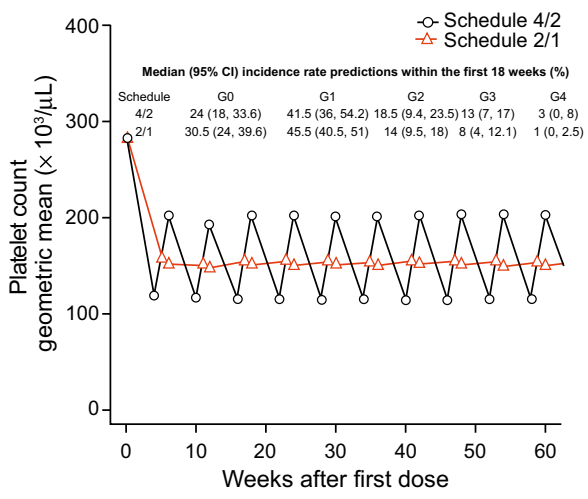

D Absolute lymphocyte count

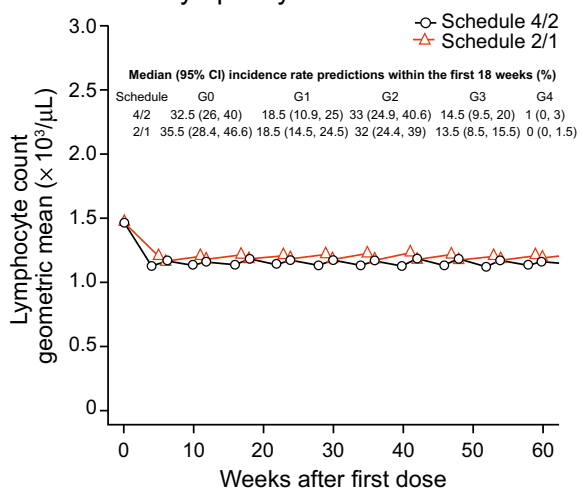

F Absolute neutrophil count

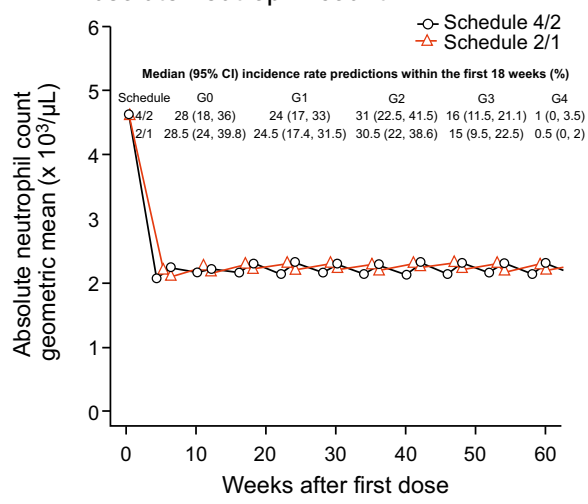

H Diastolic blood pressure

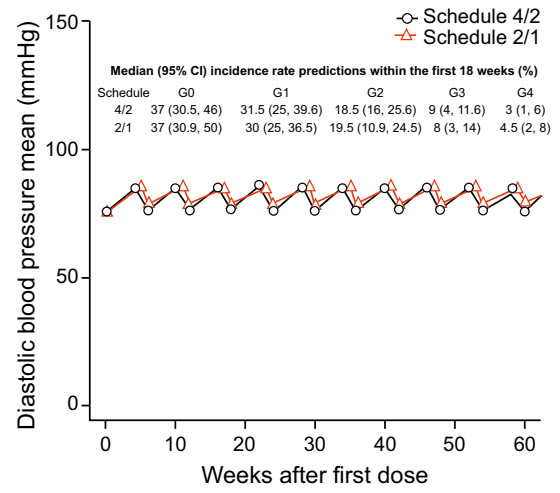


supported by the diagnostic plots, which indicated a lack of consistent noticeable differences in key $\mathrm{PK}$ or PK/PD parameters for Schedule 2/1 or $2 / 2$ versus Schedule 4/2. The advantage of NONMEM analysis is that it enables the pooling of patients bearing different characteristics because the covariates (tumor, sex, schedule, etc.) are integrated into the model. The PK and PK/PD models were indeed verified and validated by VPC using both the working and validation datasets, bootstrapping techniques, and plotting of predicted population values versus observed population values. The PK/PD models used were mainly semi-mechanistic PK/PD models with TCSFL or mechanism-based IDR models as described by Danhof et al. [30]. These models offer the advantage of including target-site distribution, target binding and activation, PD interactions, transduction, and homeostatic feedback mechanisms.

PK parameter values for sunitinib and its metabolite estimated by the models used in this study agree well with values estimated by other PK models in the literature [31] and those reported in clinical studies in healthy volunteers [32]. Trough plasma concentrations of sunitinib of approximately $50 \mathrm{ng} / \mathrm{mL}$ were predicted by the models for the two schedules and are in broad agreement with measured trough plasma concentrations previously reported $[33,34]$. The higher CL/F and $V_{\mathrm{c}} / F$ values in GIST patients compared with RCC patients is mostly likely due to the lower bioavailability of sunitinib in GIST patients compared with RCC patients. This lower bioavailability in GIST could be caused by the fact that the site of disease in GIST is potentially impacting the absorption of sunitinib from the GI tract. The covariates identified for $\mathrm{CL} / F$ and $V_{\mathrm{c}} / F$ in the sunitinib final $\mathrm{PK}$ model, as well as the SU012662 final model, were plausible and relevant and most have been previously reported by Houk et al. [31].

Similarly, the majority of the covariates identified for key parameters in the final PK/PD models for different endpoints appeared to be plausible and relevant. For example, for the efficacy endpoint SLD, it is highly plausible that patients with poor performance status (i.e. ECOG $\mathrm{PS} \geq 1$ ) will have a greater target tumor SLD at baseline. Similarly, the fact that the $\mathrm{EC}_{50}$ for efficacy was higher in patients on Schedule CDD versus the intermittent dosing schedule was also consistent with the clinical data indicating lower PFS and ORR in patients on Schedule CDD compared with patients on Schedule 4/2 [8]. Furthermore, the $\mathrm{EC}_{50}$ for efficacy (i.e. the SLD) was significantly higher for GIST compared with RCC (i.e. 177 vs. $30.5 \mathrm{ng} / \mathrm{mL}$ ), consistent with a lower observed PFS and ORR in GIST compared with RCC following sunitinib therapy.

Although the intersubject variability in PK was low to moderate, there was a large degree of intersubject variability associated with the $\mathrm{EC}_{50}$ for efficacy, as well as the safety endpoints, indicating that establishing a universal therapeutic window or target plasma concentration for therapeutic drug monitoring purposes would not be feasible. Therefore, the curent approach to start patients with the $50 \mathrm{mg}$ dose and then allow for dose adjustments (i.e. incremental dose increase or decrease) based on individual patient safety tolerability appears to be an appropriate and practical approach and ensures that every patient achieves optimal plasma exposures.

Our model predicted that sunitinib, regardless of schedule, reduced target lesion SLD. Likewise, sunitinib was predicted to induce neutropenia, a small reduction in LVEF, lymphocytopenia, and fluctuating ALT, AST, and DBP, all known AEs associated with sunitinib $[2,6,16]$. In a pivotal trial comparing sunitinib versus interferon- $\alpha$ as first-line treatment in patients with advanced RCC, sunitinib was administered on Schedule 4/2 [6]; however, due to drug toxicity, more than $35 \%$ of patients in this trial underwent dose interruptions, and more than $30 \%$ had dose reductions. Subsequently, research efforts have been undertaken to identify optimal dosage schedules, and a number of retrospective reports regarding the efficacy and safety of Schedule $2 / 1$ in RCC have been published. For example, Miyake et al. [27] and Najjar et al. [14] showed that, in RCC patients switched from Schedule 4/2 to Schedule 2/1, the incidence of AEs decreased after the switch. In both studies, sunitinib-induced thrombocytopenia-related AEs of grade 3 or higher were experienced in a significantly smaller proportion of patients on Schedule 2/1 than Schedule 4/2 [14, 27]. Grade 3 or higher AEs related to leukopenia and hypertension associated with sunitinib treatment, were experienced by a similar number of patients administered at either of the two schedules [27]. In the study of Najjar et al. [14], leukopenia-related AEs were experienced by fewer sunitinib-treated patients on Schedule 2/1, but this difference did not reach statistical significance. Two other retrospective studies reported no loss of efficacy with sunitinib in patients switched from Schedule 4/2 to Schedule 2/1 due to AEs [11, 12]; however, given the design of these studies, their results must be interpreted with caution. In another retrospective comparison of the two sunitinib schedules, Kondo et al. [13] observed that, with Schedule 2/1, fewer patients required dose interruptions due to AEs, and ORR and PFS were similar between the two schedules. In that same study, fewer patients experienced thrombocytopenia-related AEs of grade 3 or higher when on Schedule 2/1, but this was not statistically significant.

\section{Conclusions}

Good agreement was observed between our model predictions and reported clinical data in patients with advanced RCC treated with sunitinib on Schedule $4 / 2$ or 
2/1. Similar findings were also observed in patients with GIST, although clinical data for Schedule $2 / 1$ in GIST are lacking. Sunitinib Schedule 2/1 dosing offers a potential alternative to Schedule $4 / 2$ as it allows for management of toxicity without loss of efficacy.

Author Contributions Consent to submit has been received explicitly from all co-authors, as well as from the responsible authorities tacitly or explicitly at the institute/organization where the work has been carried out, before the work was submitted. Authors whose names appear on the submission have contributed sufficiently to the scientific work and therefore share collective responsibility and accountability for the results.

\section{Compliance with Ethical Standards}

Funding The work described in this manuscript was sponsored by Pfizer, Inc. Medical writing support was provided by Andy Gannon and Thierry Deltheil at ACUMED ${ }^{\circledR}$, an Ashfield company, part of UDG Healthcare plc (New York, NY, USA), with funding from Pfizer, Inc. Editorial support was provided by Vardit Dror, PhD, of Engage Scientific Solutions and funded by Pfizer, Inc.

Conflicts of interest Reza Khosravan is a full-time employee of Pfizer and holds Pfizer stock. Robert J. Motzer has received consultancy fees from Pfizer and Novartis, and research funding from Pfizer, Novartis, Genentech, and GlaxoSmithKline. Elena Fumagalli has reported no potential conflicts of interest. Brian I. Rini has received consultancy fees and research funding from Pfizer.

Open Access This article is distributed under the terms of the Creative Commons Attribution-NonCommercial 4.0 International License (http://creativecommons.org/licenses/by-nc/4.0/), which permits any noncommercial use, distribution, and reproduction in any medium, provided you give appropriate credit to the original author(s) and the source, provide a link to the Creative Commons license, and indicate if changes were made.

\section{References}

1. Faivre S, Demetri G, Sargent W, et al. Molecular basis for sunitinib efficacy and future clinical development. Nat Rev Drug Discov. 2007;6:734-45.

2. Demetri GD, van Oosterom AT, Garrett CR, et al. Efficacy and safety of sunitinib in patients with advanced gastrointestinal stromal tumour after failure of imatinib: a randomised controlled trial. Lancet. 2006;368:1329-38.

3. Motzer RJ, Agarwal N, Beard C, et al. NCCN clinical practice guidelines in oncology: kidney cancer. J Natl Compr Canc Netw. 2009;7:618-30

4. Motzer RJ, Hutson TE, Tomczak P, et al. Overall survival and updated results for sunitinib compared with interferon alfa in patients with metastatic renal cell carcinoma. J Clin Oncol. 2009;27:3584-90.

5. Kalra S, Rini BI, Jonasch E. Alternate sunitinib schedules in patients with metastatic renal cell carcinoma. Ann Oncol. 2015;26:1300-4.

6. Motzer RJ, Hutson TE, Tomczak P, et al. Sunitinib versus interferon alfa in metastatic renal-cell carcinoma. N Engl J Med. 2007;356:115-24.

7. Escudier B, Roigas J, Gillessen S, et al. Phase II study of sunitinib administered in a continuous once-daily dosing regimen in patients with cytokine-refractory metastatic renal cell carcinoma. J Clin Oncol. 2009;27:4068-75.

8. Motzer RJ, Hutson TE, Olsen MR, et al. Randomized phase II trial of sunitinib on an intermittent versus continuous dosing schedule as first-line therapy for advanced renal cell carcinoma. J Clin Oncol. 2012;30:1371-7.

9. George S, Blay JY, Casali PG, et al. Clinical evaluation of continuous daily dosing of sunitinib malate in patients with advanced gastrointestinal stromal tumour after imatinib failure. Eur J Cancer. 2009;45:1959-68.

10. Houk BE, Bello CL, Poland B, et al. Relationship between exposure to sunitinib and efficacy and tolerability endpoints in patients with cancer: results of a pharmacokinetic/pharmacodynamic meta-analysis. Cancer Chemother Pharmacol. 2010;66:357-71.

11. Atkinson BJ, Kalra S, Wang X, et al. Clinical outcomes for patients with metastatic renal cell carcinoma treated with alternative sunitinib schedules. J Urol. 2014;191:611-8.

12. Bjarnason GA, Khalil B, Hudson JM, et al. Outcomes in patients with metastatic renal cell cancer treated with individualized sunitinib therapy: correlation with dynamic microbubble ultrasound data and review of the literature. Urol Oncol. 2014;32:480-7.

13. Kondo T, Takagi T, Kobayashi H, et al. Superior tolerability of altered dosing schedule of sunitinib with 2-weeks-on and 1-weekoff in patients with metastatic renal cell carcinoma-comparison to standard dosing schedule of 4-weeks-on and 2-weeks-off. Jpn J Clin Oncol. 2014;44:270-7.

14. Najjar YG, Mittal K, Elson P, et al. A 2 weeks on and 1 week off schedule of sunitinib is associated with decreased toxicity in metastatic renal cell carcinoma. Eur J Cancer. 2014;50:1084-9.

15. Saponara M, Lolli C, Nannini M, et al. Alternative schedules or integration strategies to maximise treatment duration with sunitinib in patients with gastrointestinal stromal tumours. Oncol Lett. 2014;8:1793-9.

16. Lindauer A, Di Gion P, Kanefendt F, et al. Pharmacokinetic/ pharmacodynamic modeling of biomarker response to sunitinib in healthy volunteers. Clin Pharmacol Ther. 2010;87:601-8.

17. Motzer RJ, Michaelson MD, Redman BG, et al. Activity of SU11248, a multitargeted inhibitor of vascular endothelial growth factor receptor and platelet-derived growth factor receptor, in patients with metastatic renal cell carcinoma. J Clin Oncol. 2006;24:16-24.

18. Motzer RJ, Rini BI, Bukowski RM, et al. Sunitinib in patients with metastatic renal cell carcinoma. JAMA. 2006;295: 2516-24.

19. Barrios CH, Hernandez-Barajas D, Brown MP, et al. Phase II trial of continuous once-daily dosing of sunitinib as first-line treatment in patients with metastatic renal cell carcinoma. Cancer. 2012;118:1252-9.

20. Uemura H, Shinohara N, Yuasa T, et al. A phase II study of sunitinib in Japanese patients with metastatic renal cell carcinoma: insights into the treatment, efficacy and safety. Jpn J Clin Oncol. 2010;40:194-202.

21. Demetri GD, Heinrich MC, Fletcher JA, et al. Molecular target modulation, imaging, and clinical evaluation of gastrointestinal stromal tumor patients treated with sunitinib malate after imatinib failure. Clin Cancer Res. 2009;15:5902-9.

22. Shirao K, Nishida T, Doi T, et al. Phase I/II study of sunitinib malate in Japanese patients with gastrointestinal stromal tumor after failure of prior treatment with imatinib mesylate. Invest New Drugs. 2010;28:866-75.

23. Demetri GD, Garrett CR, Schoffski P, et al. Complete longitudinal analyses of the randomized, placebo-controlled, phase III trial of sunitinib in patients with gastrointestinal stromal tumor following imatinib failure. Clin Cancer Res. 2012;18:3170-9. 
24. Therasse P, Arbuck SG, Eisenhauer EA, et al. New guidelines to evaluate the response to treatment in solid tumors. European Organization for Research and Treatment of Cancer, National Cancer Institute of the United States, National Cancer Institute of Canada. J Natl Cancer Inst. 2000;92:205-16.

25. Beal S, Sheiner LB, Boeckmann A, et al. NONMEM user's guides (1989-2009). Ellicott City: Icon Development Solutions; 2009.

26. Lee JL, Kim MK, Park I, et al. RandomizEd phase II trial of Sunitinib four weeks on and two weeks off versus Two weeks on and One week off in metastatic clear-cell type REnal cell carcinoma: RESTORE trial. Ann Oncol. 2015;26:2300-5.

27. Miyake H, Harada K, Miyazaki A, et al. Improved health-related quality of life of patients with metastatic renal cell carcinoma treated with a 2 weeks on and 1 week off schedule of sunitinib. Med Oncol. 2015;32:78.

28. Krajewski KM, Franchetti Y, Nishino M, et al. 10\% Tumor diameter shrinkage on the first follow-up computed tomography predicts clinical outcome in patients with advanced renal cell carcinoma treated with angiogenesis inhibitors: a follow-up validation study. Oncologist. 2014;19:507-14.

29. Thiam R, Fournier LS, Trinquart L, et al. Optimizing the size variation threshold for the $\mathrm{CT}$ evaluation of response in metastatic renal cell carcinoma treated with sunitinib. Ann Oncol. 2010;21:936-41.

30. Danhof M, de Jongh J, De Lange EC, et al. Mechanism-based pharmacokinetic-pharmacodynamic modeling: biophase distribution, receptor theory, and dynamical systems analysis. Annu Rev Pharmacol Toxicol. 2007;47:357-400.

31. Houk BE, Bello CL, Kang D, et al. A population pharmacokinetic meta-analysis of sunitinib malate (SU11248) and its primary metabolite (SU12662) in healthy volunteers and oncology patients. Clin Cancer Res. 2009;15:2497-506.

32. Bello CL, Sherman L, Zhou J, et al. Effect of food on the pharmacokinetics of sunitinib malate (SU11248), a multi-targeted receptor tyrosine kinase inhibitor: results from a phase I study in healthy subjects. Anticancer Drugs. 2006;17:353-8.

33. Lankheet NA, Kloth JS, Gadellaa-van Hooijdonk CG, et al. Pharmacokinetically guided sunitinib dosing: a feasibility study in patients with advanced solid tumours. $\mathrm{Br} \mathrm{J}$ Cancer. 2014;110:2441-9.

34. Lankheet NA, Knapen LM, Schellens JH, et al. Plasma concentrations of tyrosine kinase inhibitors imatinib, erlotinib, and sunitinib in routine clinical outpatient cancer care. Ther Drug Monit. 2014;36:326-34. 